\title{
On the complexity of surface ruptures during normal faulting earthquakes: excerpts from the 6 April 2009 L'Aquila (central Italy) earthquake $\left(M_{\mathrm{w}} 6.3\right)$
}

\author{
L. Bonini ${ }^{1}$, D. Di Bucci ${ }^{2}$, G. Toscani ${ }^{1}$, S. Seno ${ }^{1}$, and G. Valensise ${ }^{3}$ \\ ${ }^{1}$ Dipartimento di Scienze della Terra e dell'Ambiente, Università di Pavia, Pavia, Italy \\ ${ }^{2}$ Dipartimento della Protezione Civile, Rome, Italy \\ ${ }^{3}$ Istituto Nazionale di Geofisica e Vulcanologia, Rome, Italy
}

Correspondence to: D. Di Bucci (daniela.dibucci@protezionecivile.it)

Received: 13 September 2013 - Published in Solid Earth Discuss.: 14 November 2013

Revised: 11 April 2014 - Accepted: 15 April 2014 - Published: 28 May 2014

\begin{abstract}
Over the past few years the assessment of the earthquake potential of large continental faults has increasingly relied on field investigations. State-of-the-art seismic hazard models are progressively complementing the information derived from earthquake catalogs with geological observations of active faulting. Using these observations, however, requires full understanding of the relationships between seismogenic slip at depth and surface deformation, such that the evidence indicating the presence of a large, potentially seismogenic fault can be singled out effectively and unambiguously.

We used observations and models of the 6 April 2009, $M_{\mathrm{W}}$ 6.3, L'Aquila, normal faulting earthquake to explore the relationships between the activity of a large fault at seismogenic depth and its surface evidence. This very well-documented earthquake is representative of mid-size yet damaging earthquakes that are frequent around the Mediterranean basin, and was chosen as a paradigm of the nature of the associated geological evidence, along with observational difficulties and ambiguities.

Thanks to the available high-resolution geologic, geodetic and seismological data aided by analog modeling, we reconstructed the full geometry of the seismogenic source in relation to surface and sub-surface faults. We maintain that the earthquake was caused by seismogenic slip in the range $3-10 \mathrm{~km}$ depth, and that the slip distribution was strongly controlled by inherited discontinuities. We also contend that faulting was expressed at the surface by pseudo-primary
\end{abstract}

breaks resulting from coseismic crustal bending and by sympathetic slip on secondary faults.

Based on our results we propose a scheme of normal fault hierarchization through which all surface occurrences related to faulting at various depths can be interpreted in the framework of a single, mechanically coherent model. We stress that appreciating such complexity is crucial to avoiding severe over- or under-estimation of the local seismogenic potential.

\section{Introduction}

Starting in the 1980s many workers have attempted to infer the earthquake potential of large continental faults from their surface length and displacement (see Kim and Sanderson, 2005 for a review). As a result, over the past two decades several empirical relationships between earthquake magnitude and the extent of surface ruptures have been developed (e.g., Wells and Coppersmith, 1994; Wesnousky, 2008) and have since become the most popular analytical tool in earthquake geology.

On the one hand, these relationships have certainly helped in quantifying field geological observations, ultimately allowing them to be incorporated in analytical earthquake and seismic hazard assessment models (e.g., Stirling et al., 2013). In fact, the assessment of the hazard posed by large continental faults is increasingly relying on field investigations on all scales, and even a worldwide initiative for seismic hazard 
assessment such as the Global Earthquake Model (GEM) has "Gathering all knowledge on active faults worldwide" as one of its founding pillars (http://www.globalquakemodel.org/ what/seismic-hazard/active-faults-database/). On the other hand, however, these empirical relationships have also contributed to put in the background the complexity of the relationships between the seismogenic source at depth and its surface expression. As a reminder to geologists, nature has recently spawned a number of damaging earthquakes that turned out to have been generated by blind, hidden, or otherwise hard-to-identify faults (e.g., Jan 2010, Haiti, $M_{\mathrm{w}} 7.0$; Sep 2010-Feb 2011, Darfield-Christchurch, New Zealand, $M_{\mathrm{w}}$ 7.1-6.3; Oct 2011, Van, eastern Turkey, $M_{\mathrm{w}} 7.1$; JulyAugust 2013).

The $M_{\mathrm{w}}$ 6.3, 6 April 2009 L'Aquila (Abruzzi, central Italy) earthquake belongs to this category. Although the L'Aquila region had long been known for its high seismicity level along with most of Abruzzi, the 2009 earthquake challenged the standard approach for surface active fault identification because (1) clearly visible surface faults, that prior to 2009 were presumed to be active, showed no genetic relationships with the seismogenic source, and only some showed negligible reactivation; and (2) post-earthquake field analyses documented only limited and discontinuous coseismic surface ruptures.

The 2009 event is currently one of the best documented continental extensional earthquakes worldwide, and hence it makes a first-rate case for exploring the relationships between the activity of a seismogenic normal fault and its surface evidence in a structurally complex area such as the Apennines.

Notwithstanding the high quality of available data, the nearly 200 papers published to date about the 2009 L'Aquila earthquake have produced widely divergent seismotectonic interpretations and models (see Table 5 in Vannoli et al., 2012, for a summary).

We used a wealth of high-resolution geological, geodetic and seismological data combined with analog modeling to reconstruct the geometry of the seismogenic rupture in relation to sub-surface and surface faults. We aimed at devising a scheme for active fault hierarchization that explains all surface outcomes of shallow crustal seismogenic faulting in the framework of a single, mechanically coherent interpretative model. Proper appreciation of such complexity forms the basis for a correct assessment of the local earthquake potential.

\section{Tectonic setting}

The Italian Apennines exhibit a remarkably complex structure resulting from the overprinting of a number of subsequent tectonic phases (Fig. 1). In the early Mesozoic the region was part of the African passive margin of the Tethys Ocean; it hosted large carbonate platforms and intervening pelagic basins that were subsequently broken up by $\mathrm{E}-\mathrm{W}$
Triassic-Lower Jurassic extension (Calamita et al., 2011; Di Domenica et al., 2014). Since the Cretaceous, the region evolved within the framework of the convergent motion between the African and European plates; east- to northeastverging thrusts along with their associated foredeep/thrusttop basins progressed toward the Adriatic foreland up to the Middle Pleistocene (Patacca and Scandone, 1989) and were subsequently dissected by strike-slip and normal faulting.

Following a major geodynamic change at $\sim 800 \mathrm{ka}, \mathrm{SW}-$ NE extension became the dominant tectonic style over the core of the Apennines (e.g., Hyppolite et al., 1994; Galadini, 1999), as demonstrated also by breakout, seismicity and crustal strain data (e.g., Montone et al., 2012; Carafa and Barba, 2013). Extension is definitely a youthful process in the Apennines, however, and proceeds at the relatively slow rate of 2-3 $\mathrm{mm} \mathrm{yr}^{-1}$ (D' Agostino et al., 2011). In contrast, the core of the Apennines is undergoing vigorous regional-scale uplift at $1-2 \mathrm{~mm} \mathrm{yr}^{-1}$ (D'Anastasio et al., 2006); this process induces fast exhumation and widespread differential erosion of the Meso-Cenozoic rocks comprising it, being by far more effective than extension in building and modifying the landscape. As a result of these competing processes, the Apennines landscape is largely dominated by the older compressional structures (Fig. 1), which tend to be emphasized by erosion despite their being inactive: some even simulate the typical basin-and-range landforms associated with the action of a mature normal fault, according to a process of geomorphological convergence referred to as "mimicking" (Valensise and Pantosti, 2001). In addition to that, and due to the combined effect of tectonic stress and gravity, extended terrains often exhibit a level of complexity that makes the correct hierarchization of active normal faults - or even their mere identification - extremely challenging. On the outcrop scale, a large normal fault of crustal significance, a shallow reactivated normal fault on the backlimb of older thrust sheets, or an even shallower sackung scarp may appear equally evident and similarly convincing as to the existence of an underlying major seismogenic source (Gori et al., 2014).

\section{The 6 April 2009 earthquake}

The 6 April 2009 L'Aquila earthquake struck a seismically very active portion of the Apennines chain. It came as the culmination of a long foreshock/aftershock sequence recorded by permanent and temporary INGV seismometers (Chiarabba et al., 2009; Chiaraluce et al., 2011). The earthquake caused intensity up to IX-X MCS effects in a small number of villages located southeast of L'Aquila, but the largest number of collapsed buildings and casualties was reported in L'Aquila itself.

Extensive albeit limited coseismic surface breaks were reported by several workers over a $100 \mathrm{~km}^{2}$ region elongated in the NW-SE direction between L'Aquila and Monticchio, 

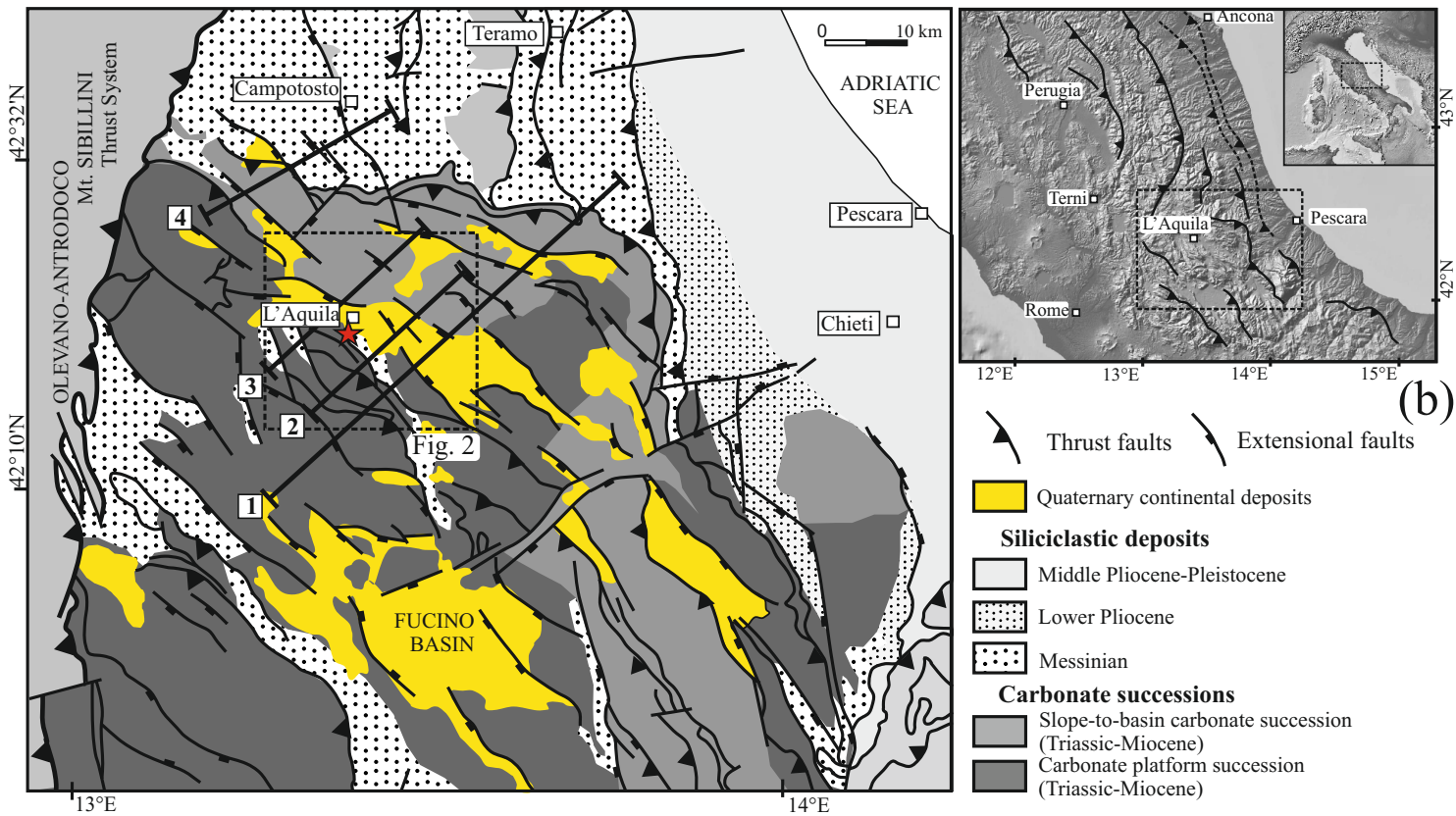

(a)

Figure 1. (a) Tectonic map of the Abruzzi region (modified from Vezzani et al., 2009). The present morphology of the axial portion of the Apennines is still dominated by the folding and thrusting through which the chain was built up over a long time interval between the upper Miocene and the middle Pleistocene. Subsequent extension and intervening sedimentation in intermontane basins has so far only slightly modified the compressional architecture of the Apennines. A dashed box indicates the exact location of the study area. 1, 2, 3, and 4 indicate cross sections. (b) Digital elevation model of the central Apennines, showing the trend of the main thrust fronts. A number of secondary fronts are also clearly delineated by the topography.

about $15 \mathrm{~km}$ to the southeast (see detailed descriptions in Boncio et al., 2010; the Emergeo Working Group, 2010, and Vittori et al., 2011). The most continuous surface breaks were extensional cracks, some with a maximum net throw of a few centimeters, often seen at the top of a $\sim 10$ m-high scarp formed by Quaternary continental deposits and running above the village of Paganica (Fig. 3).

DInSAR measurements based on extensive Envisat and COSMO-SkyMed data sets constrained by scattered GPS observations revealed sizable coseismic crustal deformation resulting in bowl-shaped, gently asymmetric surface subsidence peaking at 15-20 cm (Atzori et al., 2009; D'Agostino et al., 2012; Cheloni et al., 2014; Fig. 4). All published coseismic slip models agree that most coseismic slip - up to $1.0 \mathrm{~m}$ - occurred between $9-10$ and 3-4 km in depth, whereas slip in the shallowest crust was found to be $0.1 \mathrm{~m}$ or less over most of the fault length (e.g., Atzori et al., 2009; Cirella et al., 2009; Cheloni et al., 2010; D'Agostino et al., 2012; Cheloni et al., 2014). Shallower slip was documented mainly near the northern end of the fault (D'Agostino et al., 2012), about $3 \mathrm{~km}$ to the northeast of L'Aquila (Fig. 4).

$P$ and $S$ wave analyses pointed out that the main rupture corresponded to an asperity located in a high-velocity layer $\left(\mathrm{Vp}>6 \mathrm{~km} \mathrm{~s}^{-1}\right.$ and $\mathrm{Vs} \sim 4.2 \mathrm{~km} \mathrm{~s}^{-1}$; from Bianchi et al., 2010 and Di Stefano et al., 2011, respectively). This high-velocity body has been interpreted as being composed of partially hydrated mafic rocks between $3-4$ and $10 \mathrm{~km}$ in depth (Fig. 4c), although in nearby areas the observed $\mathrm{Vp}$ and Vs values correspond to the characteristic velocities of the Meso-Cenozoic limestones and terrigenous rocks (Chiarabba et al., 2010; Di Stefano et al., 2011).

The sequence is well described by a detailed doubledifference catalog of relocated events (3000 events with $M \geq$ 1.9 from Chiaraluce et al., 2011; 64000 events of all magnitudes from Valoroso et al., 2013). When coupled with moment tensor solutions for the largest shocks $\left(\mathrm{M}_{w} \geq 2.7\right.$; Herrmann et al., 2011), these data allow imaging of individual faults activated during this complex sequence in great detail (Fig. 4). In the depth interval 3-4 to $10 \mathrm{~km}$ the aftershocks align rather regularly along a $\sim 9 \mathrm{~km}$ wide, single planar surface dipping $45-50^{\circ}$ to the $\mathrm{SW}$ over the entire fault length and extending for $\sim 16 \mathrm{~km}$ in the NW-SE direction. Some shallower aftershocks (i.e., above $3-4 \mathrm{~km}$ in depth) are seen around the northern end of the fault; even though they are rather scattered, their locations highlight the activation of minor high-angle faults. In contrast, no shallow aftershocks are seen along the central and southern portions of the fault.

While the models based on seismological and geodetic data agree with fault parameters at depth (for both fault geometry and coseismic slip distribution), those based on 


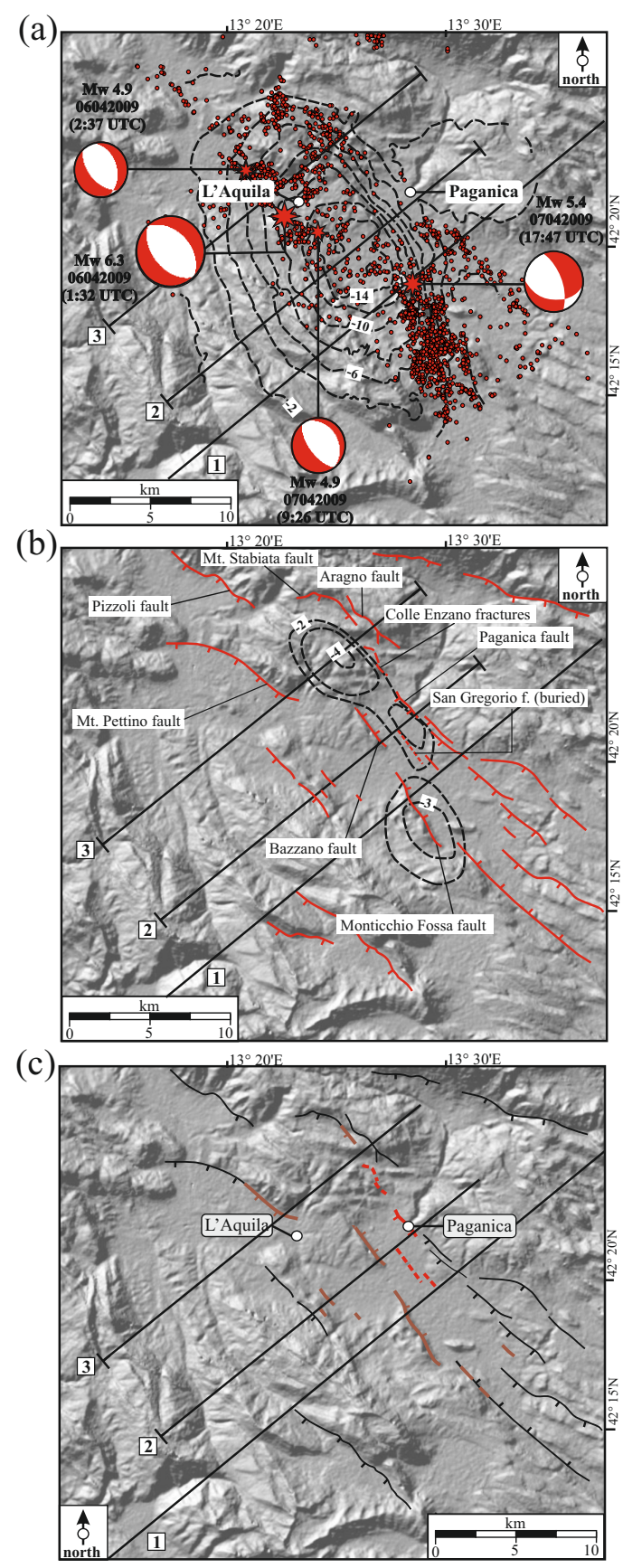

Figure 2. (a) Map view of the L'Aquila area showing the location (red stars) and focal mechanisms of the largest events of the 2009 sequence (Scognamiglio et al., 2010). Dashed lines are contours of elevation changes observed between 4 and 12 April 2009 (D’Agostino et al., 2012). Red dots indicate relocated aftershocks (Chiaraluce et al., 2011). (b) Presumed active faults, shown by red lines. S1 and S2 indicate the traces of cross sections 1 and 2. Dashed lines are contours of the elevation changes observed between 12 April and 5 October 2009 (D'Agostino et al., 2012). (c) Faults reported as activated during the 2009 earthquake. Those shown in red are discontinuous fractures mapped close to the Paganica fault; black lines are presumed active faults and brown segments represent the portion of the faults reported as partially reactivated in 2009 (Emergeo Working Group, 2010). coseismic surface ruptures showed widely divergent results, especially regarding the net throw and the lateral extent of surface ruptures, respectively, ranging from none to about $10 \mathrm{~cm}$ and from 2.6 to $19 \mathrm{~km}$ (see Fig. 14 in Vittori et al., 2011, and Table 5 in Vannoli et al., 2012).

\section{Buried tectonic structures in the L'Aquila area from geological and seismological data}

To investigate the buried tectonic setting of the Apennines in the L'Aquila area we combined (1) surface geological data from various sources (e.g., Vezzani et al., 2009; see Fig. 1), (2) a three-dimensional distribution of geological units at depths derived from seismic tomography (Di Stefano et al., 2011), and (3) a reconstruction of the extensional active fault systems obtained from aftershock locations and moment tensor solutions (Herrmann et al., 2011; Valoroso et al., 2013).

Cross- and down-dip sections of the L'Aquila region (Fig. 5) show its intricate structural framework. Such complexity is not surprising in view of the overall structure of the Abruzzi Apennines, which were built by progressive stacking of heterogeneous thrust sheets. Strong lateral variations occur within each tectonic unit, mainly due to the architecture inherited from the Mesozoic extensional tectonics, and most tectonic structures of this part of the Apennines thrust belt are not cylindrical but exhibit a rather complex shape. These circumstances result in a complex lateral distribution of rock volumes that may have significant geometric and rheological implications for contemporary deformation.

The extensional faults activated during the 2009 seismic sequence lie in the hanging wall of the large Gran Sasso thrust. The upper tip of the main fault surface (at $\sim 3-$ $4 \mathrm{~km}$ ) coincides with a distinct lithological change. Aftershock alignments, focal mechanisms, and receiver function analyses highlighted the presence of a discontinuity striking $\mathrm{N} 334^{\circ}$ and dipping $20^{\circ}$ towards SW near the upper tip of the fault. When coupled with the distribution of geological units, such a discontinuity can be interpreted as a thrust plane that appears to play a primary role in the development of the newly formed extensional faults. In the northwestern part of the study area just above this plane there is a change in fault geometry, whereas in the central (cross sections 2 and 3 in Fig. 5) and southern parts (cross section 1) of the study area the aftershocks are confined below it. In our view this observation alone prevents the coseismic ruptures mapped at the surface (e.g., the Paganica ruptures) from being simply connected with the seismogenic fault identified at depth.

To shed light on the genetic relationships between the master fault at depth and surface structures we simulated the evolution of a normal fault using analog models. 

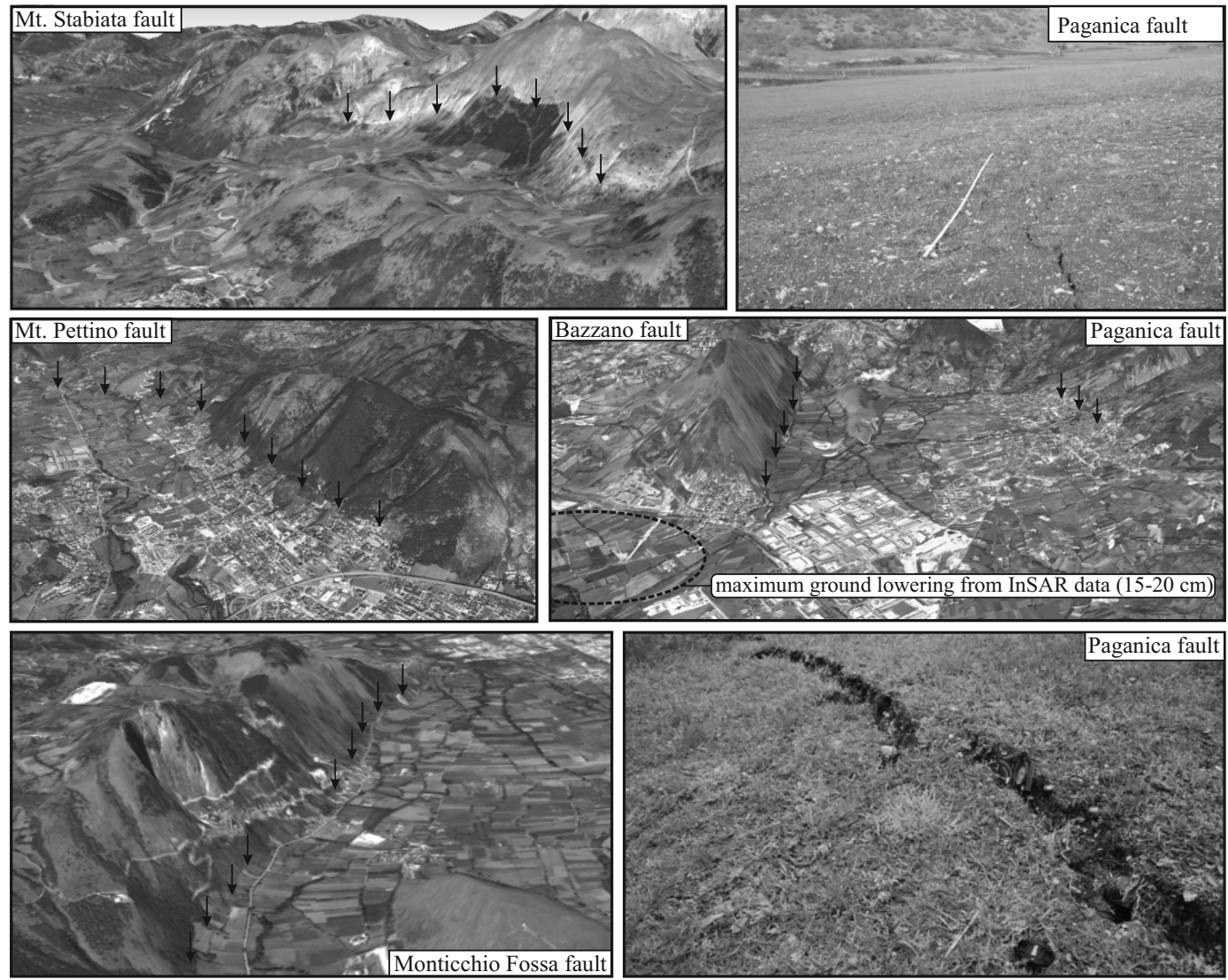

Figure 3. Landscape view of the faults in the L'Aquila area (2x vertical exaggeration). On the right the Paganica fault (central image) with two details of the surface ruptures (upper and lower panels) recognized after the 2009 earthquake (Emergeo Working Group, 2010).

\section{Deep and surface fault patterns: an analog experiment perspective}

To analyze the mid- to long-term evolution of an upward propagating blind normal fault and the associated secondary structures related to the bending of the overlying rocks we constructed a series of analog models. We chose wet clay and dry sand as our preferred analog materials; this allowed us to reproduce different aspects of the faulting process and to make the most out of the characteristics of both these materials. Recent studies compared results obtained using wet clay and dry sand (e.g., Eisenstadt and Sims, 2005; Withjack and Schlische, 2006; Withjack et al., 2007), highlighting differences and similarities. On the one hand, wet clay has been used extensively to analyze brittle deformation related to folding (e.g., Cloos, 1968; Withjack and Jamison, 1986; Withjack and Schlische, 2006; Henza et al., 2010; Miller and Mitra, 2011), and its effectiveness as analog material has been stressed recently by new rheological tests (Cooke and van der Elst, 2012). On the other hand, dry sand is the most commonly used material for modeling tectonic deformation (see Graveleau et al., 2012 for a review). Using these two different materials allowed us to explore if and how the rhe- ological differences between the two materials, and primarily the cohesion, affect our observations. All the experiments took place in a normal gravity field.

\subsection{Pre-existing mechanical discontinuities and fault evolution: wet kaolin experiments}

Our first goal was to understand if and how low-angle mechanical discontinuities affect the upward propagation of a normal fault. As a clay type we used kaolin with $65 \%$ water content. Wet kaolin has a shear strength in the range 40 to $100 \mathrm{~Pa}$ (Eisenstadt and Sims, 2005; Cooke and van der Elst, 2012: Cooke et al., 2013) and its frictional coefficient is about 0.6. Following well-established scaling laws (e.g., Hubbert, 1937; Schellart, 2000), these parameters imply that $1 \mathrm{~cm}$ in the experiment represents about $1 \mathrm{~km}$ in nature.

The deformation device is composed of two plates (Fig. 6); one remains fixed throughout the experiment, thus representing the footwall, whereas the other one is pulled by a stepper-motor simulating hanging-wall subsidence. The displacement rate was fixed at $0.005 \mathrm{~mm} \mathrm{~s}^{-1}$, a strain rate that is considered appropriate for wet clay experiments (e.g., Cooke and van der Elst, 2012). The apparatus has the top and both sides free so as to prevent undesired boundary effects. 

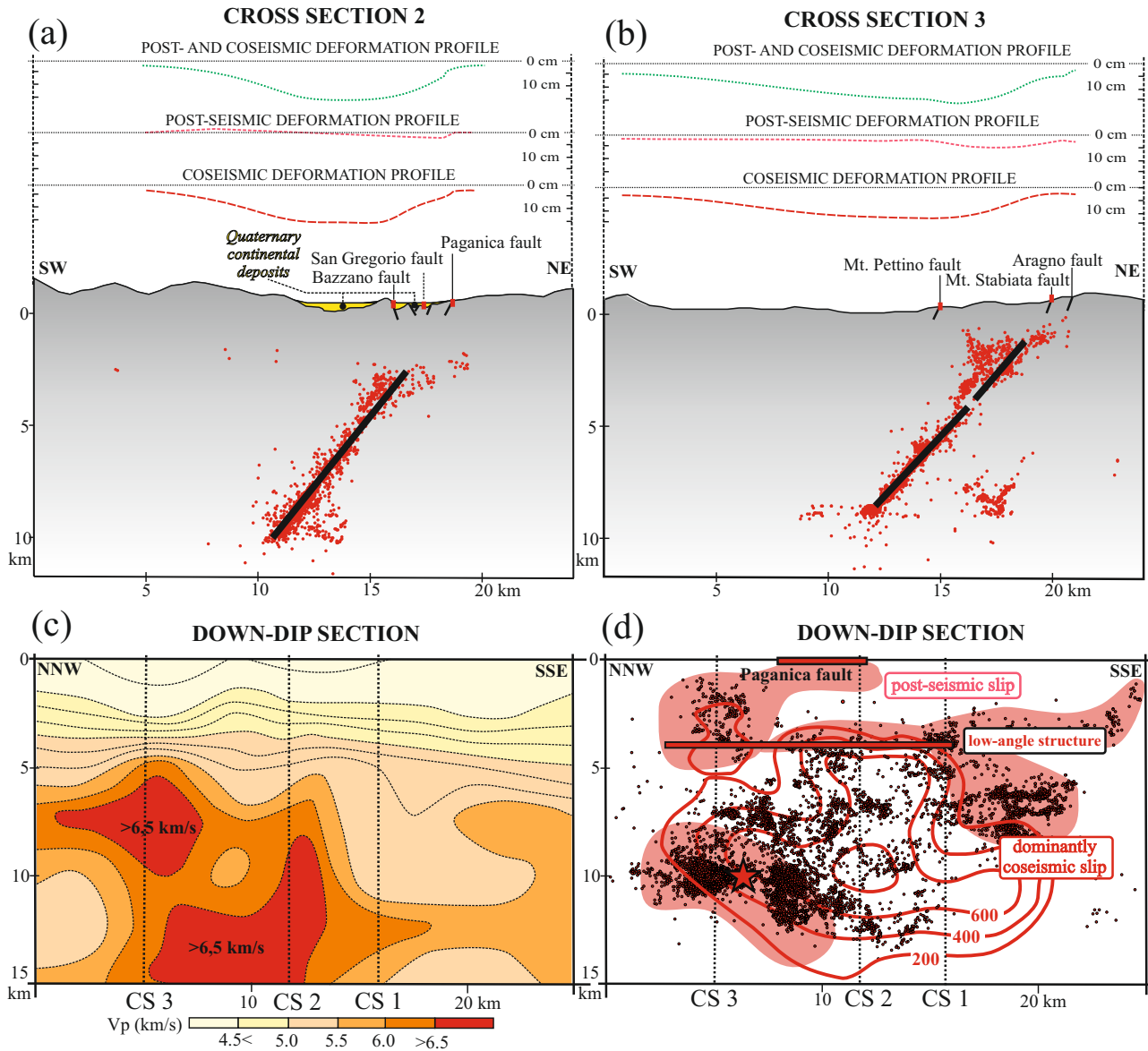

(d)

DOWN-DIP SECTION

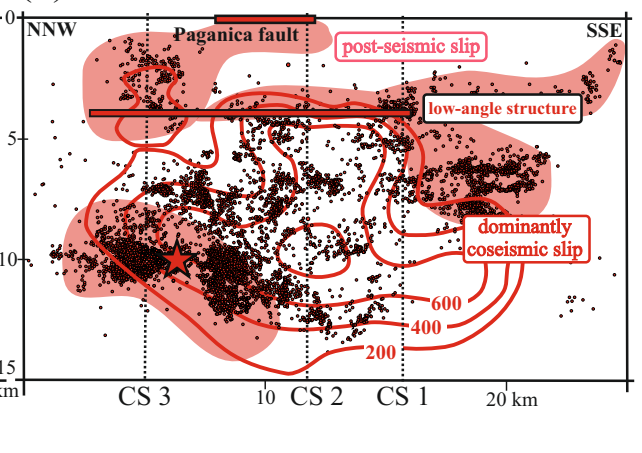

Figure 4. (a) and (b): cross sections, showing dominantly coseismic (4 April 2009-12 April 2009; D'Agostino et al., 2012), post-seismic (12 April-5 October 2009; D'Agostino et al., 2012) and cumulative elevation changes measured along the section trace. In all figures red dots indicate relocated aftershocks (Valoroso et al., 2013). Thick black lines represent the fault plane derived by geodetic inversions with coseismic slip (Atzori et al., 2009). Section traces are shown in Figs. 1 and 2. (c) and (d): down-dip sections along the L'Aquila master fault (strike N135E; dip 50 to the WSW); (c) shows Vp values imaged along the fault plane (from Di Stefano et al., 2011); (d) shows the mainshock location (star). Red dots are aftershocks located within $0.5 \mathrm{~km}$ of the fault plane (Chiaraluce et al., 2011). Coseismic slip pattern, shown by red lines (contour interval is $200 \mathrm{~mm}$; Atzori et al., 2009), and location of the inferred inherited thrust faults (orange thick lines). Red areas mark portions of the fault that experienced post-seismic slip (modified from D'Agostino et al., 2012).

An experiment is terminated when the upward-propagating faults reach the surface of the model. To monitor and quantify the deformation we took lateral photographs every $1 \mathrm{~mm}$ of displacement. To this end we used displacement image correlation (DIC) analyses, a non-destructive, non-invasive, high-resolution optical technique that has the capability to detect any subtle motion of the model material during the experiments.

The clay experiments were carried out based on two experimental configurations: the first, Wet Kaolin \#1 (WK1), representing a buried fault growing in a homogeneous setting (Fig. 6a); the second, Wet Kaolin \#2 (WK2), similar to the previous one but with a low-angle discontinuity placed along the presumed propagating trajectory of the master fault (Fig. 6b). Such a pre-existing discontinuity has been reproduced by sliding an electrified blade through the analog ma- terial. This innovative procedure, which has been successfully tested by Cooke et al. (2013), allowed us to introduce in the model very thin discontinuities that simulate pre-existing fault systems. Figures 7 and 8 show significant steps selected from the two experiments, though both experiments are photographed at every $1 \mathrm{~mm}$ of displacement. The initial thickness of the WK models is $5 \mathrm{~cm}$, representing the shallower $5 \mathrm{~km}$ of a generic continental crust.

At the beginning of both experiments $(0.1 \mathrm{~mm})$, the displacement fields showed a triangular deformation zone (Figs. 7a and 8a), corresponding to the trishear zone described and modeled by several investigators (e.g., Erslev, 1991; Hardy and Ford, 1997; Jin and Groshong, 2006). The displacement field showed by the two experiments during the very first deformation step is very similar, confirming that the 


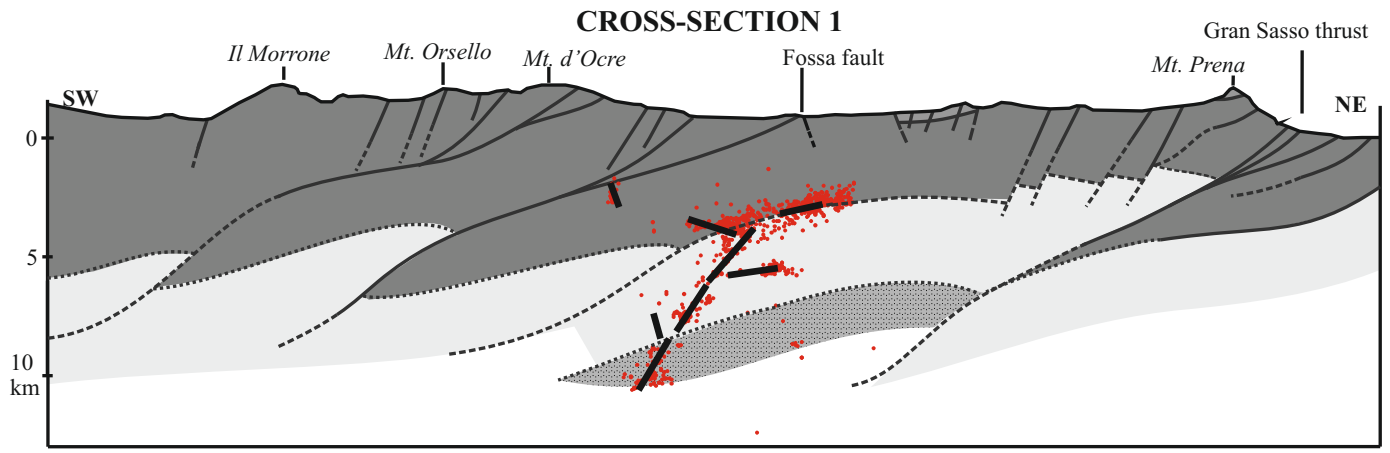

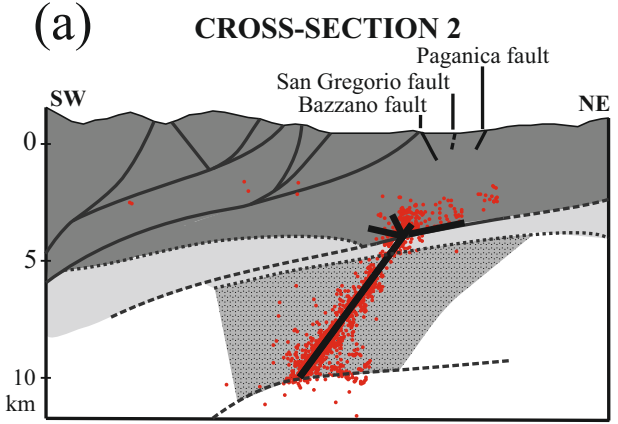

(b)

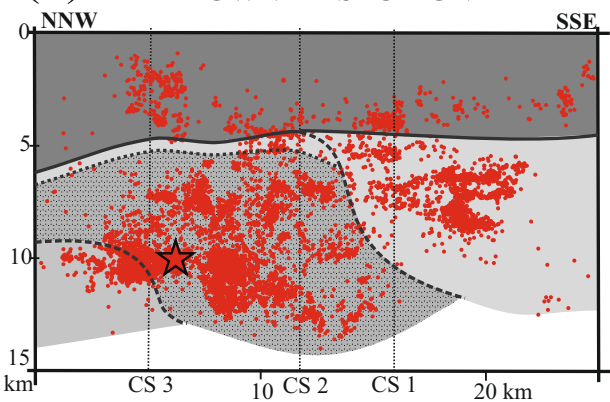

(d)

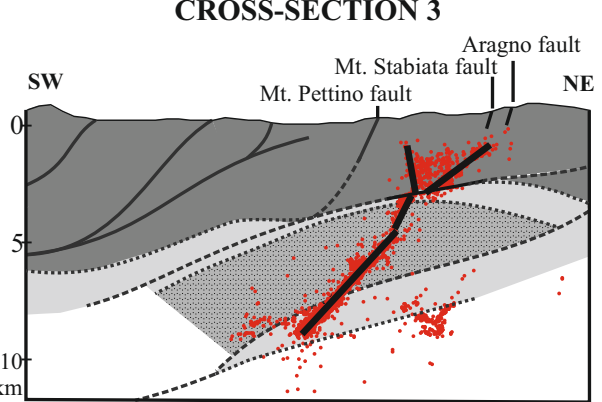

(c)

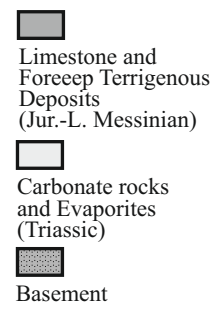

Figure 5. Geological sections across the L'Aquila area. (a) Regional geological section showing the main tectonic features of the area (modified after Satolli and Calamita, 2008 and Vezzani et al., 2009). (b) and (c): geological sections across the central (b) and northern (c) parts of the L'Aquila seismogenic source. (d) Down-dip section (strike N135E; dip $50^{\circ}$ to the WSW). In all sections red dots indicate relocated aftershocks (Valoroso et al., 2013). In all figures thick black lines represent fault segments from Valoroso et al. (2013) based on the analysis of the aftershock locations and focal mechanisms. Red star is the hypocenter of the April 6 mainshock.

mechanical properties of the analog material are the same in both wet kaolin experiments.

As displacement proceeds, brittle and ductile deformation taking place in the experiments begins to be visible. A monoclinal structure developed during both experiments after a displacement of $10 \mathrm{~mm}$ (Figs. 7b and 8b). In WK1, three synthetic faults and one antithetic extensional fault are formed at the tip of the master fault with a Mode II mechanism (Scholz, 1990). As a result of bending, two crestal fractures formed with a Mode I mechanism at the surface of the model (Fig. 7b), where tensile stress is maximal. A strain distribution analysis corroborates our observations showing two high-strain areas, a lower one and an upper one, spatially corresponding to the previously described brittle structures. At the same displacement level $(10 \mathrm{~mm})$ WK2 showed a different development of brittle structures (Fig. 8b). An individual upward-propagating fault stemming from the buried tip of the master fault appeared more developed than those seen in WK1 (Fig. 9a) and with a steeper dip angle. When this fault encountered the pre-existing discontinuity, it stopped its propagation, splitting into two minor elements. Meanwhile, minor faults were seen to displace the pre-existing low-angle plane. Also in this experiment, some downward-propagating faults related to the bending developed at the surface of the model (Fig. 8b). Strain analyses confirmed the previous observations highlighting a narrow zone where strain is highest; significantly, there is a sudden decrease in the strain value 
(a)

$$
\text { Experiment Wet Kaoline \#1 (WK1) }
$$

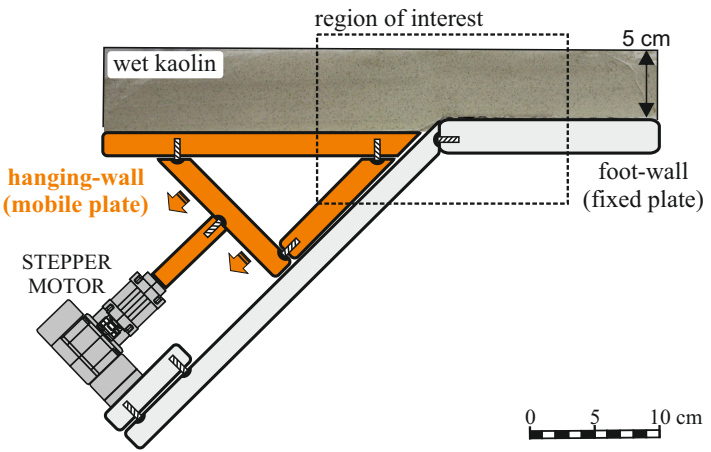

(b) Experiment Wet Kaoline \#2 (WK2)

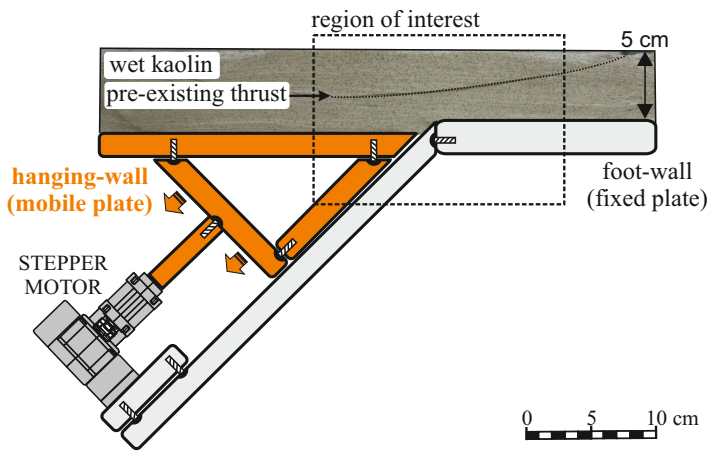

Figure 6. Experimental setup used to model (a) a fault evolving into a medium configuration and (b) with a low-angle discontinuity.

WK1 - total displacement $1.0 \mathrm{~mm}$ (D.I.C. from 0 to $0.1 \mathrm{~mm}$ )

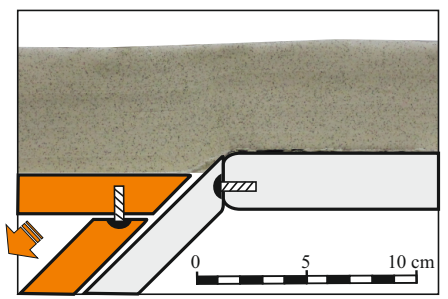

(a)

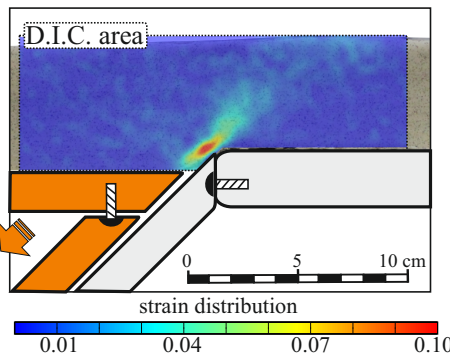

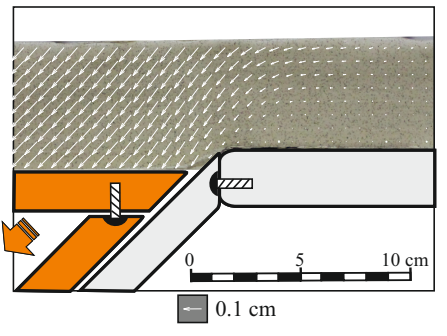

WK1 - total displacement $10.0 \mathrm{~mm}$ (D.I.C. from 9 to $10 \mathrm{~mm}$ )

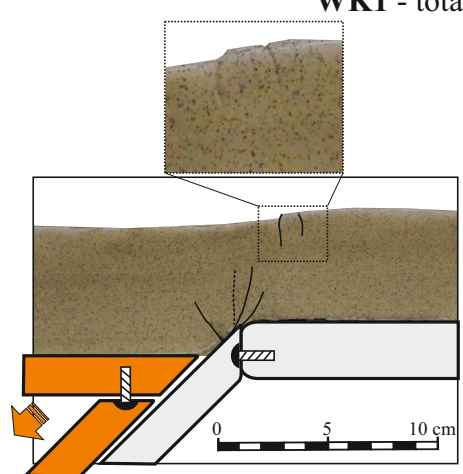

(b)
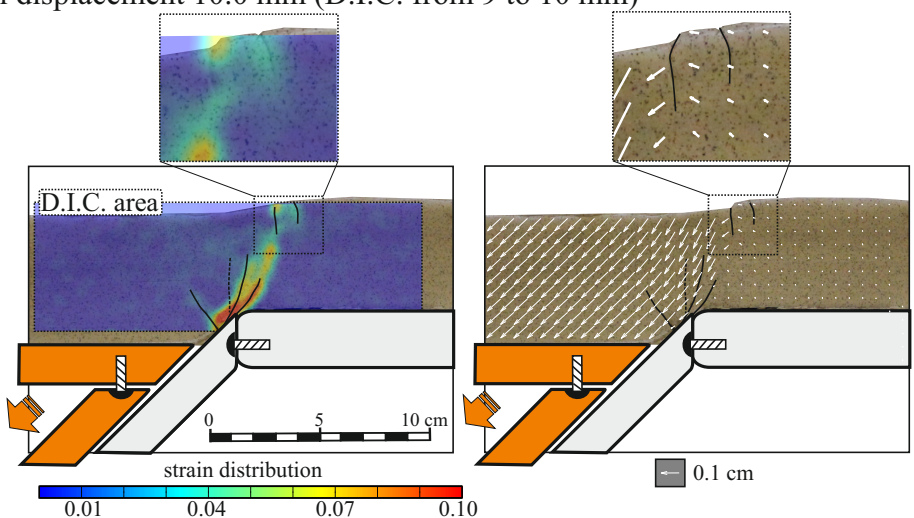

WK1 - total displacement $15.0 \mathrm{~mm}$ (D.I.C. from 14 to $15 \mathrm{~mm}$ )

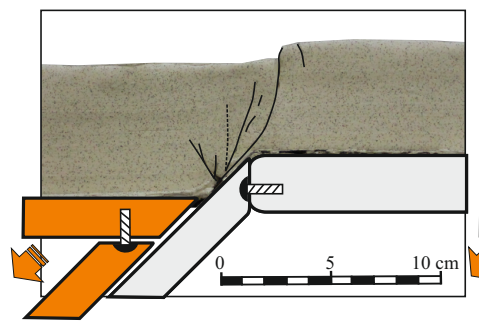

(c)
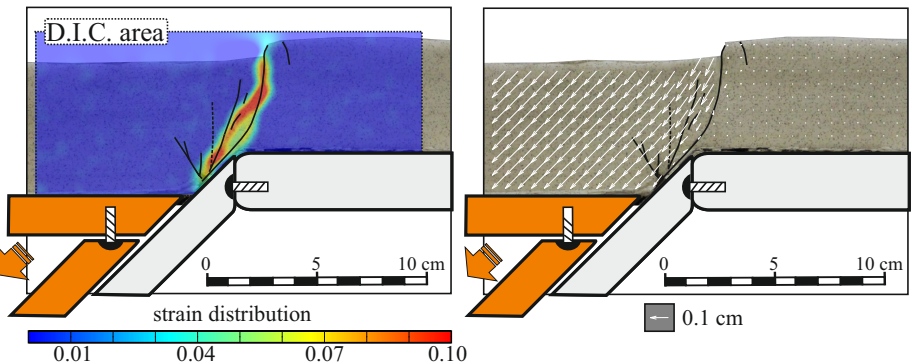

Figure 7. Progressive evolution of the fault patterns in the WK1 wet clay experiment (left panels). For each step the brittle and ductile deformations have been analyzed using the DIC technique, which returned the displacement field (right panels) and the strain distribution (central panels). Dashed lines indicate precursor faults (see text). 
WK2 - total displacement $0.1 \mathrm{~mm}$ (D.I.C. from 0 to $0.1 \mathrm{~mm}$ )

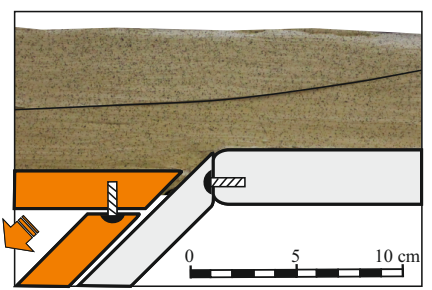

(a)

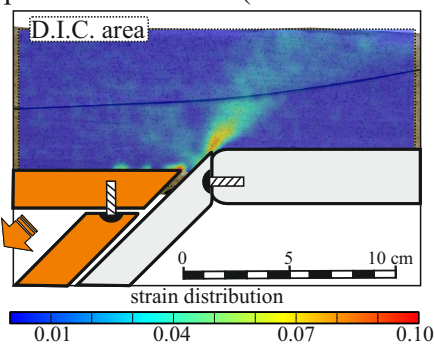

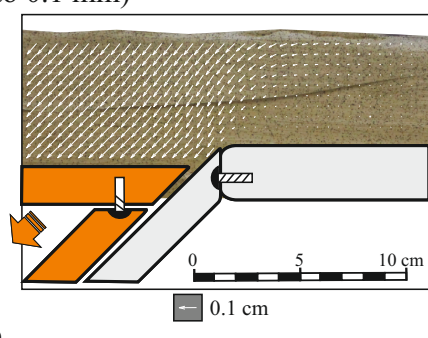

WK2 - total displacement $10.0 \mathrm{~mm}$ (D.I.C. from 9 to $10 \mathrm{~mm}$ )

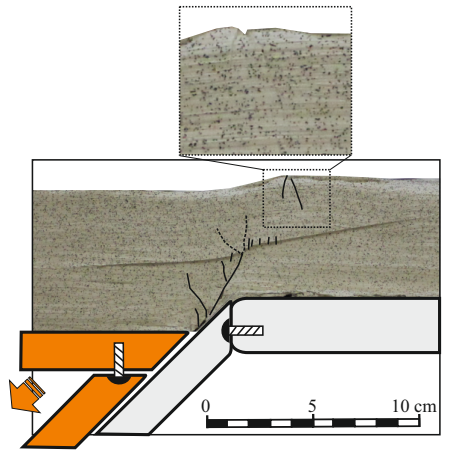

(b)
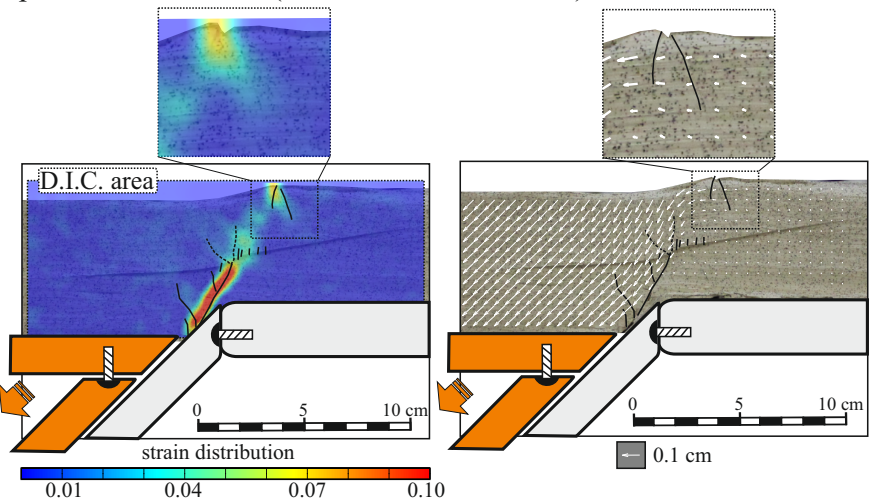

WK2 - total displacement $15.0 \mathrm{~mm}$ (D.I.C. from 14 to $15 \mathrm{~mm}$ )
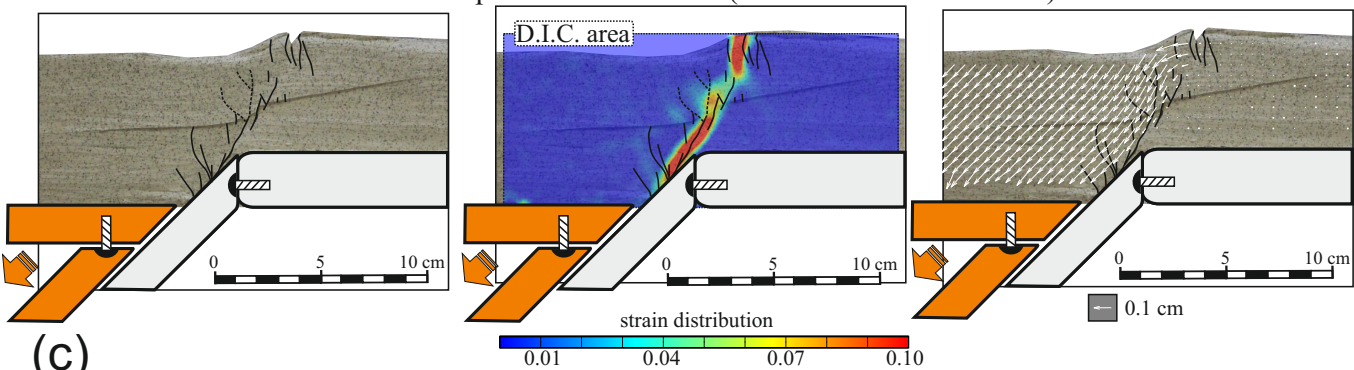

(c)

WK2 - total displacement $25.0 \mathrm{~mm}$ (D.I.C. from 24 to $25 \mathrm{~mm}$ )

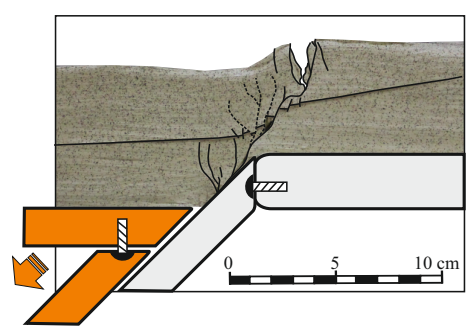

(d)
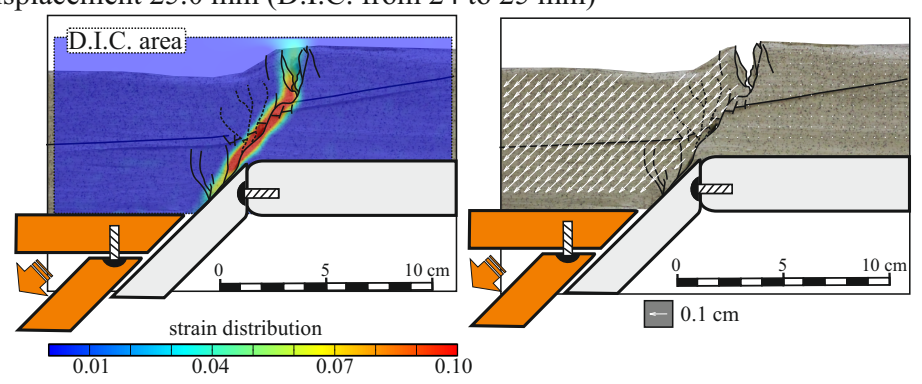

Figure 8. Progressive evolution of the fault patterns in the WK2 wet clay experiment (left panels). For each step the brittle and ductile deformations have been analyzed using the DIC technique, which returned the displacement field (right panels) and the strain distribution (central panels). Dashed lines indicate precursor faults.

where the upward-propagating fault intersects the low-angle plane.

After $15 \mathrm{~mm}$ of displacement, in WK1 the upwardpropagating fault reached the surface, connecting with one of the downward-propagating faults and showing an overall listric geometry (Fig. 7c); the connection of the two structures is well predicted by the strain distribution analysis. In contrast, in WK2 the downward- and upward-propagating faults do not appear to have connected at the same displacement step (Fig. 8c). This different behavior must necessarily be related to the role played by the low-angle discontinuity; a circumstance confirmed by the strain analysis, which shows that most of the deformation remains confined below the discontinuity. The rate of upward propagation of the 
(a)
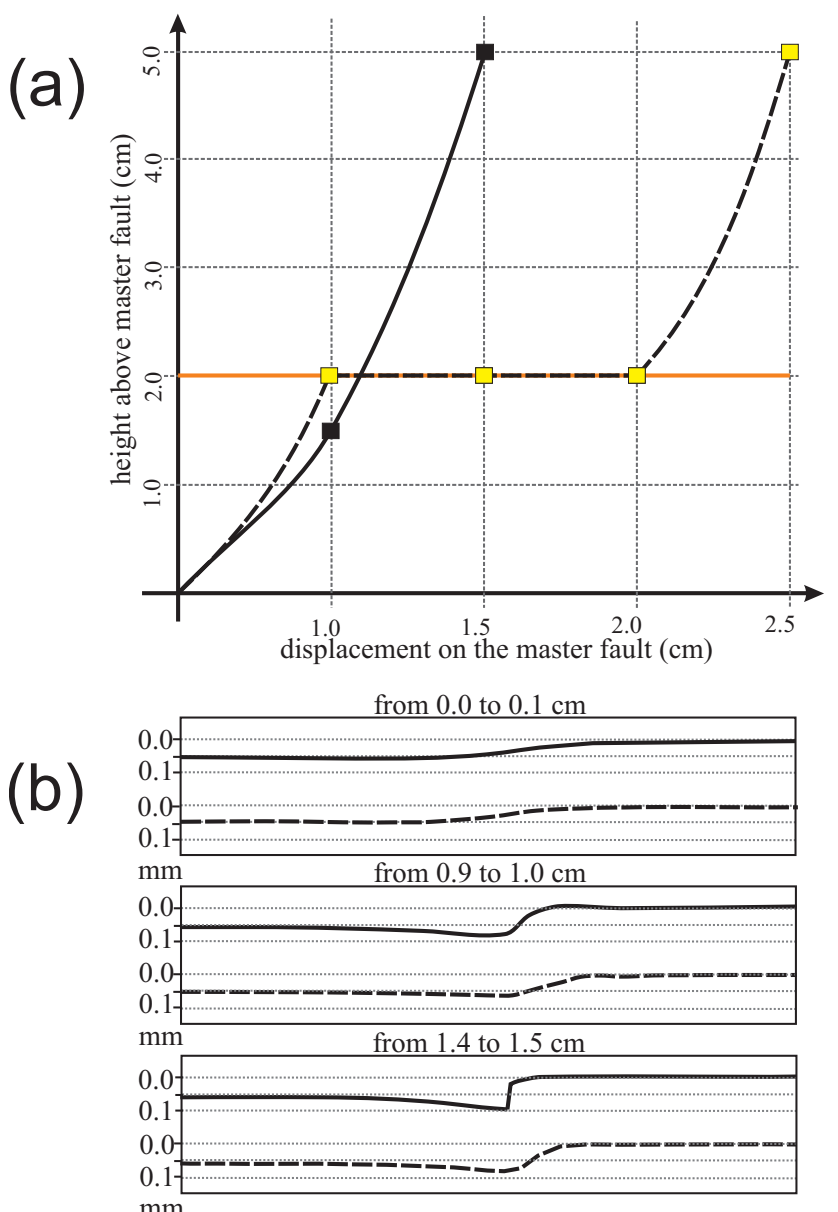

(c)

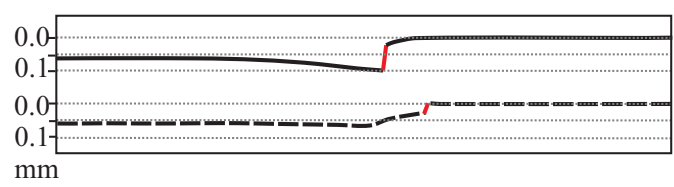

Figure 9. (a) Diagram showing the vertical location of the upper tip of the upward-propagating faults against the amount of displacement on the master fault. Thick black and dashed lines represent results from WK1 and WK2, respectively. Orange lines represent the location of the pre-existing discontinuity in WK2. (b) Topography profiles of the WK1 (thick black lines) and WK2 (dashed lines) experiments at different intervals. (c) Final topographic profile of the wet clay experiments, showing the location of the surface-breaking faults (red lines). Data in diagrams (b) and (c) come from the DIC analyses shown in Figs. 7 and 8 (right panels).

fault in WK2 is much slower than in WK1, and downwardpropagating faults in WK2 are more developed than in WK1 (Fig. 9a).

Notice that in WK2 a direct link between upward- and downward-propagating faults was reached only after $25 \mathrm{~mm}$ of total displacement (Fig. 8d), $10 \mathrm{~mm}$ more than was needed for WK1 (Fig. 7c), and with a peculiar ramp-flat-ramp configuration.
A comparison of the two models at this final development stage, i.e., when the upward- and downward-propagating faults are connected and the displacement produced by the two rigid blocks has reached the surface, shows significant differences. Regarding fault geometry, we observed a listric profile in WK1 and a change in dip in WK2 coincident with the pre-existing low-angle discontinuity. Such a ramp-flatramp profile in WK2 further stresses the role of the faultbend folding mechanism connected to the growth of the upward-propagating fault; as a result, the bending-moment faults are more developed in this experiment. Despite the rigidity of the blocks that simulate the hanging wall and the footwall, the faulting evolution in WK1 and WK2 produced subsiding basins having different shapes (Figs. 9b and c); while in WK1 the basin depocenter falls close to the surface-breaking fault, the depocenter of the bowl-shaped basin that developed in WK2 lies $40 \mathrm{~mm}$ away from the surface-breaking fault.

In summary, the results of the experiments show how strongly the mechanical discontinuity cut in the uniform material of the model affected the growth of the simulated master blind fault, delaying the upward propagation of the synthetic faults that developed from its tip (Fig. 9). Both experiments displayed that sub-vertical bending-moment faults are the first structures to form at the surface, as shown also by other investigators (e.g., van Gent et al., 2010). In our wet kaolin experiments, such secondary structures mainly developed with a Mode I mechanism showing an excessive width (see for example the final step of WK2; Fig. 5g), probably due to the quite high cohesion of the wet clay itself.

\subsection{Quartz sand experiments}

Although wet kaolin is very effective as an analog material, its high cohesion may result in some undesirable modeling effects. To overcome this limitation we reproduced some key features of the models made with clay using dry sand.

We performed two different experiments. The first one, Quartz Sand \#1 (QS1), used the same experimental apparatus of the wet kaolin experiments, formed by two rigid blocks, one of which is mobile and acts as a subsiding hangingwall fault block (Fig. 10a). This experiment was conceived to evaluate how much the rheological differences between wet kaolin and dry sand affect deformation patterns in an isotropic material. In the second experiment, Quartz Sand \#2 (QS2), the hanging-wall fault block was replaced by a flexing plate connected to the stepper motor. The aim of this experiment was strictly to reproduce a bending of the hanging wall caused by a slip on a blind fault (Fig. 10b). This configuration is reminiscent of the plateau phase of the upward propagation in the WK2 experiment, namely the phase when the deformation in the block on top of the low-angle discontinuity was dominated by bending rather than simple shearing (Fig. 9a). The low cohesion of the quartz sand was expected 
(a) Experiment Quartz Sand \#1 (QS1)

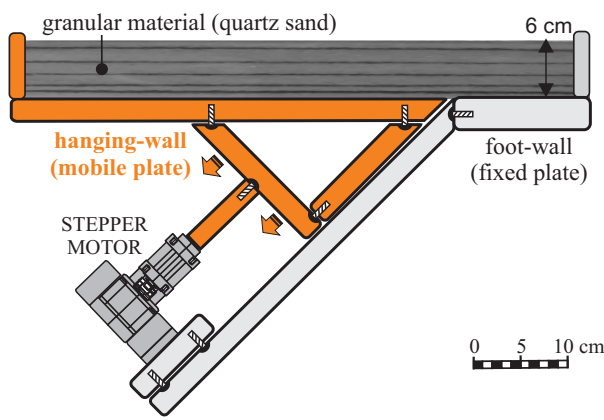

(c) Experiment Quartz Sand \#1 (QS1)

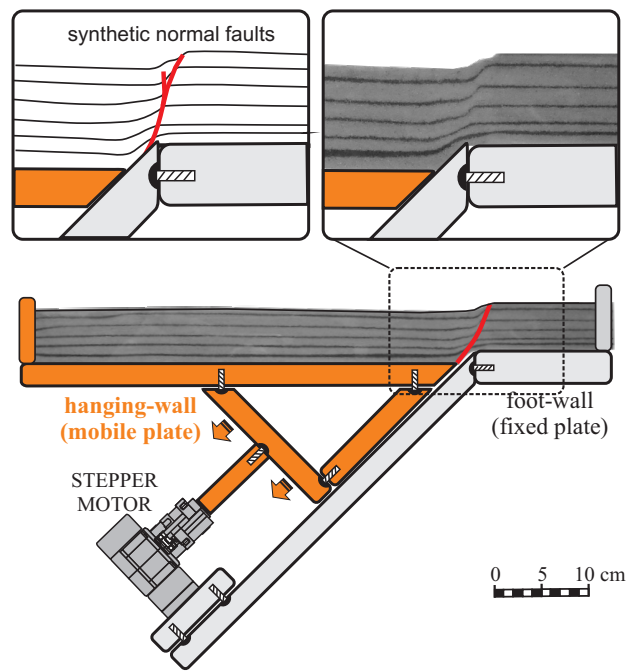

(b) Experiment Quartz Sand \#2 (QS2)

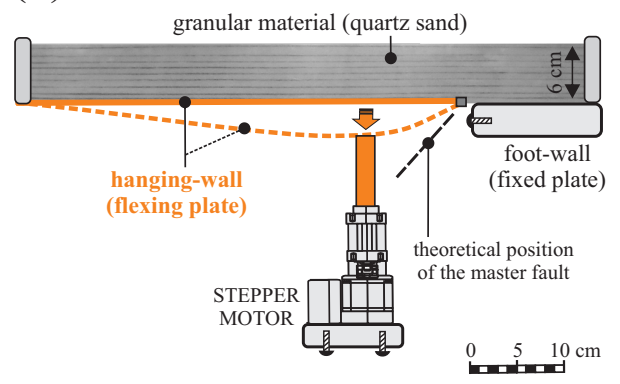

(d) Experiment Quartz Sand \#2 (QS2)

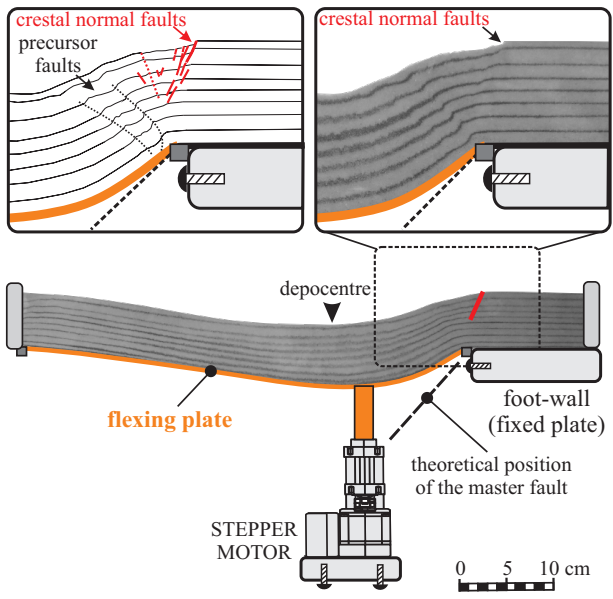

Figure 10. Analog modeling setup and results of dry sand experiments QS1 and QS2. (a) and (b) are sketches of the experimental modeling apparatus. (c) and (d) show the results of the experiment. Red lines represent newly formed faults and dashed black lines indicate precursor faults.

to prevent the unnatural generation of open cracks that we observed in WK2.

The experiment used quartz sand having the following mechanical properties: cohesion $30 \mathrm{~Pa}$, coefficient of internal friction 0.88 , angle of internal friction $41^{\circ}$. Using standard scaling rules (Hubbert, 1937), under our experimental conditions $1 \mathrm{~cm}$ represents $0.5 \mathrm{~km}$ in nature, implying that our model aimed at reproducing the shallowest $3 \mathrm{~km}$ of a continental crust. In both experiments, two lateral glass walls confined the quartz sand. To prevent undesired boundary effects, we reduced the friction by polishing the glass walls with graphite powder.

The results of QS1 did not show remarkable differences with respect to WK1; the upward-propagating fault nucleated at the upper tip of the simulated master fault and rapidly reached the surface (Fig. 10c), as already observed in several previous sand box models (e.g., Bonini et al., 2011, and references therein). The basin associated with slip on the master fault was quite similar to its equivalent in WK1.
In QS2, a forced fold developed above the tip of the hypothetical fault as a result of the imposed bending (Fig. 10d). A series of crestal fractures, some showing small but measurable vertical throw due to low cohesion of the dry sand, formed where the tensile stress was maximum, that is to say along the hypothetical up-dip prolongation of the master fault. Overall, these structures are reminiscent of the bending-moment faults seen in the wet kaolin experiments. Additionally, some upward-convex faults formed at the boundary between rigid and flexing blocks. Such structures had also been recognized in the WK models (dashed lines in Figs. 7 and 8); they are known as "precursor faults" (Mandl, 2000) and have been described as one of the first steps of brittle deformation connected to a buried fault, both in analog models and in natural examples (Mandl, 2000).

As observed in the WK models, the QS experiments also show that the relative position between the initial tip point of the master fault at depth and the surface-breaking faults (both bending-moment faults and secondary synthetic faults) is not much different. Bending-moment faults, however, are 
located in a more external position, i.e., towards the footwall, so that they appear to be aligned with the deep master fault plane even though they are not connected with it.

\section{Discussion}

Our analog models, especially WK2 and QS2, show the mechanical feasibility of a long-lived buried extensional master fault, accompanied by disconnected secondary normal faults lying at the surface roughly along its projection. Model QS2 also demonstrates that bending-moment faults developed in a low-cohesion material may display some vertical displacement, mimicking a genuine upward-propagating normal fault, and that to some extent the size and the shape of the basin related to the growth of upward-propagating faults depends on the growth rate of the faults (Fig. 9).

Based on the available data about the L'Aquila sequence and on our modeling results, we conclude that the low-angle discontinuity that exists around $3 \mathrm{~km}$ depth played an active role in preventing coseismic slip from propagating to the surface, ultimately affecting the mid- to long-term evolution of the shallow portion of the entire fault system.

We believe that our results cast doubts on the nature of the surface fractures detected after the 2009 L'Aquila earthquake, in particular on the interpretation of the Paganica fault as the primary expression of seismogenic faulting at depth. In the following we discuss this point analyzing the available seismological and geological evidence in the light of our modeling results. We will address in detail what is seen in different portions of the fault system.

\subsection{The Paganica fault: upward or downward propagating?}

To address this question we move from the evidence supplied by the aftershock pattern. In this respect we wish to recall that, although very shallow aftershocks were imaged between 1 and $3 \mathrm{~km}$ depth near the northern end of the seismogenic source, no aftershocks where observed between the surface and 2-3 km depth in its central portion, i.e., near Paganica (Chiarabba et al., 2009; Chiaraluce et al., 2011; Chiaraluce, 2012; Valoroso et al., 2013). This could be well explained by the velocity strengthening behavior of faults at shallow crustal depth, that is to say, in the upper stability transition (UST) zone defined by Scholz (1988), but two additional explanations are equally likely: (1) the fault normal stress, which controls the effective coefficient of friction of the rupture, might be especially low in the shallowest portion of the fault plane, thus generating stable sliding (e.g., Brace and Byerlee, 1970); or, more simply, (2) there is no fault plane continuity in the shallowest $2-3 \mathrm{~km}$ of the crust in the Paganica area. It is well known that the UST zone is not always found in seismogenic areas; for instance, Marone and Scholz (1988) investigated continental faults and concluded that the UST occurs only in mature fault zones. As a result, young faults and faults with long recurrence intervals or negligible gouge zones do not exhibit a UST zone.

Unfortunately, neither field nor trenching observations allow the nature of the Paganica fault gouge to be assessed, as the only available information consists of extensional and shear joints nearby the village of Paganica. Paleoseismological investigations across the Paganica fault used standard trenches dug in loose Quaternary deposits up to $4 \mathrm{~m}$ in depth (e.g., Cinti et al., 2011) that did not reach the bedrock (i.e., the pre-Quaternary carbonate rocks). A seismic refraction and resistivity survey run perpendicular to the Aterno Valley south of L'Aquila (Improta et al., 2012) did constrain the shape of the basin at depth; the characteristics and effective penetration depth (around $300 \mathrm{~m}$ ) of the selected methodology, however, do not allow one to draw firm conclusions on whether or how the surface ruptures extend at depth, or to understand the mechanical properties of the hypothetical fault gouge.

In summary, there is no surface exposure of the Paganica fault that could be used to state whether or not this fault is well developed at depth. Moreover, even if we considered the Paganica extensional and shear joints as secondary branches of the seismogenic source reaching the surface, we would expect afterslip along these features to result from velocity strengthening hours or days after the mainshock (e.g., Perfettini and Ampuero, 2008). Luckily, we know exactly the timing of the surface breakage near Paganica, as the PaganicaTempera aqueduct high-pressure pipe, which crosses the Paganica fault not far from the village center, was reported broken during the mainshock (Vittori et al., 2011). Hence this effect is incompatible with afterslip along a secondary branch of the main seismogenic fault.

As stated earlier, our experiments demonstrated the mechanical feasibility of a long-lived buried extensional master fault with disconnected secondary normal faults lying roughly along the same hypothetical plane: a configuration that reproduces satisfactorily all information available on the current setting and on the presumed evolution of the Paganica surface rupture. We hence interpret the Paganica breaks as tensional and shear joints that accommodate the deformation within the surface fold induced by the buried master fault.

\subsection{Northern end of the L'Aquila fault system}

With regard to the northern end of the fault system activated in 2009, the aftershock distribution indeed appears to delineate a master fault plane and its associated shallow secondary structures (Fig. 3a). These may resemble a set of secondary splays of a master fault approaching the surface. As shown by the results of the WK2 experiment, however, this would imply that this portion of the fault system is more developed than the central portion.

To test this hypothesis we compared the central and northern portions of the L'Aquila fault system (Figs. 5b and c) in 
the light of distinct subsequent steps of the wet clay experiments; one could visually relate the central portion to the step shown in Fig. 3d, and the northern portion to the step of Fig. 3g. Several observations, however, make this view questionable.

Seismological data, observations of surface co- and postseismic deformation, and inferences on the morphotectonic evolution of the Aterno River Valley, all indicate that the L'Aquila fault system generated the maximum displacement in its central portion, as seen along most normal fault systems worldwide (Fig. 4). As a consequence, the secondary structures directly generated by the master fault are also expected to be more developed in its central portion, in contrast to all available observations.

A plausible explanation for this ambiguous configuration involves the reactivation of inherited extensional fault systems located close to the buried upper tip of the seismogenic master fault. As we mentioned describing the local geological setting, the Abruzzi Apennines are the result of three subsequent deformation phases: Mesozoic extension, Cenozoic compression and shortening, and Plio-Quaternary extension. The high-angle faults that we see today at the surface may be equally well related to any of these deformation events: for instance, they could be Mesozoic faults incorporated and translated within the Cenozoic thrust sheets, or normal faults that developed in the backlimbs of thrust-related anticlines during Cenozoic compression (see Scisciani et al., 2002 for a review on this topic).

We have shown that a discontinuity - specifically a thrust plane - occurs at $3 \mathrm{~km}$ depth in the crustal volume above the master fault; therefore, some of the surface faults that slipped during the 2009 sequence and that are in the hanging wall of that thrust may also be related to previous deformation phases. A feasible hypothesis for the nature of the fault system seen near the northern end of the L'Aquila fault system is the reactivation of inherited extensional faults fortuitously located near the upper tip of the seismogenic blind master fault.

We conclude by suggesting that, although most coseismic slip was confined below $3 \mathrm{~km}$ depth during the mainshock, it did trigger sympathetic slip on inherited extensional faults such as the buried portion of the Mt. Stabiata and Aragno faults. It is well known that blind earthquake ruptures impart stress on the overlying crust, possibly triggering preexisting faults (e.g., Lin and Stein, 2004). This hypothesis is supported by the post-seismic strain recovery observed just above this shallow structure (D'Agostino et al., 2012).

\subsection{A down-dip segmentation scheme of the seismogenic source}

Based on the evidence discussed above we propose (a) that the causative rupture of the 2009 L'Aquila earthquake was confined at a depth $>3 \mathrm{~km}$, and (b) that the complex interaction with inherited low-angle faults (thrusts) not only pre- vented coseismic slip from propagating upwards, but also reduced the natural mid- to long-term tendency of the master fault to reach the surface. Accordingly, we interpret the Paganica breaks as tensional and shear joints that accommodate the deformation within the fold induced by the normal fault propagation. This outcome explains both the hidden nature of the earthquake causative fault prior to 2009 and the wide scatter of rupture models described in the literature (see Vittori et al., 2011, and Vannoli et al., 2012, for a review). We also suggest that in the depth interval 3 $10 \mathrm{~km}$ the causative fault of the 2009 L'Aquila earthquake was laterally segmented due to the interaction with inherited structures. We believe that these limitations, which are due to permanent characteristics of the local geological setting, contributed to limit the fault size and hence the magnitude of the 2009 earthquake, and we expect it to have done so also through previous seismic cycles.

\subsection{Categorization of active faults}

Faulting is a complex phenomenon on all spatial and temporal scales. In the Abruzzi Apennines this complexity arises largely from (a) the superposition of a young $(<1 \mathrm{My})$ extensional tectonic regime over the outcomes of a compressional regime that built the chain by progressive thrusting over a timescale of a few million years, (b) the similarity between surface tectonic features that represent the primary outcome of the ongoing extensional regime and secondary, inherited extensional features that are commonly associated with thrusting, and (c) the progressive rejuvenation of landforms by regional uplift, a fast landscape-building process that largely outpaces the ongoing regional extension and that is also responsible for generating fault-like gravity features. An extremely well-documented earthquake such as the 2009 event, occurring in a relatively isolated intermontane depression such as the middle Aterno Valley, affords the rare possibility to investigate the interplay between these competing processes without being tricked by appearances or - even more importantly - without being ruled by dogmas.

Based on previous observations we devised a hierarchization scheme of active normal faults in the L'Aquila area (Fig. 11). Our scheme includes four categories:

I. Seismogenic fault system (i.e., the L'Aquila master fault system): fault segments that generated the mainshock. They are the main players in the assessment of ground shaking hazards.

II. Inherited subsurface faults (i.e., the low-angle thrusts located above the main planar seismogenic plane) are faults generated during previous deformation phases and in this case acting passively as segment boundaries, both horizontally and vertically, effectively limiting the size and hence the magnitude of the earthquake generated by the master fault (mainshock). As such they 


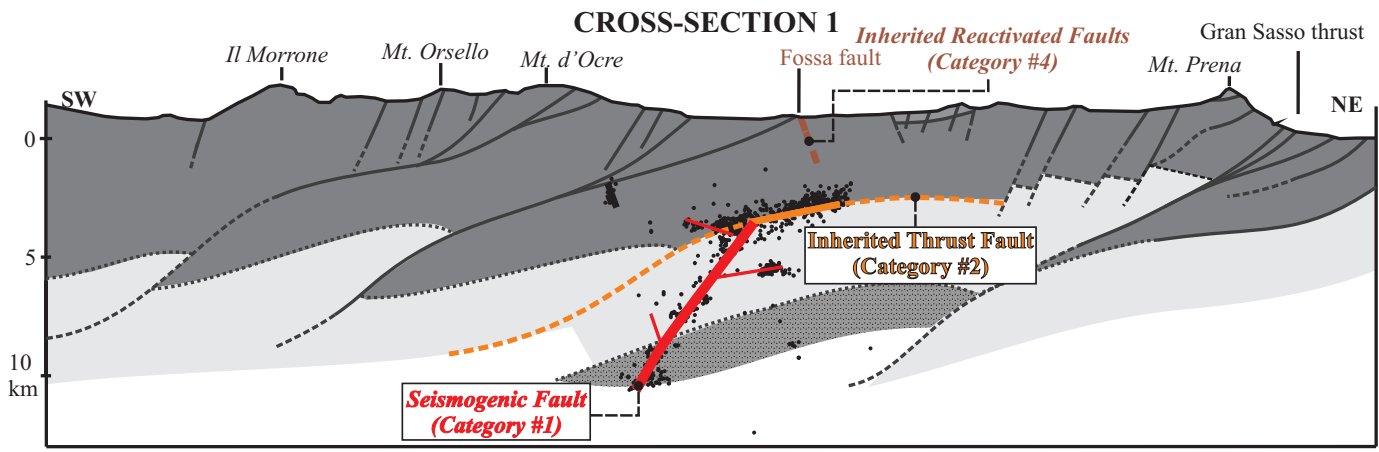

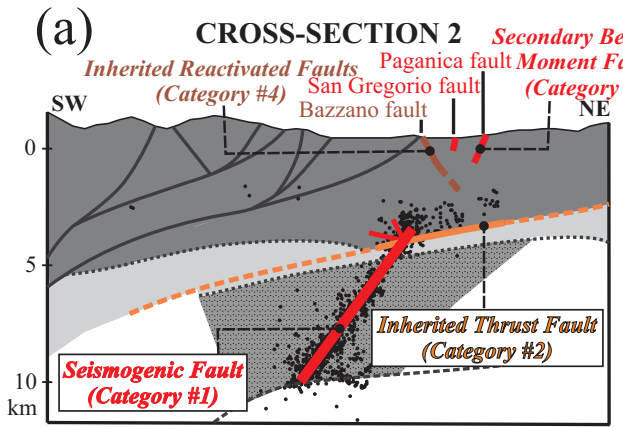

(b)
CROSS-SECTION 3

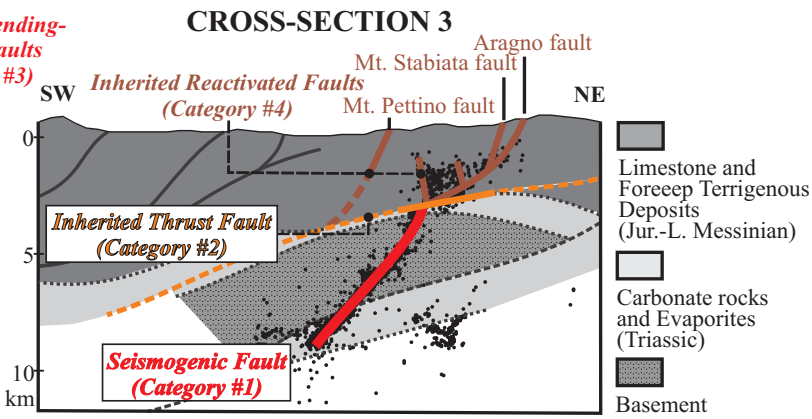

(c)

Figure 11. Geological cross sections showing different fault categories recognized in the L'Aquila area. Section traces are shown in Fig. 1.

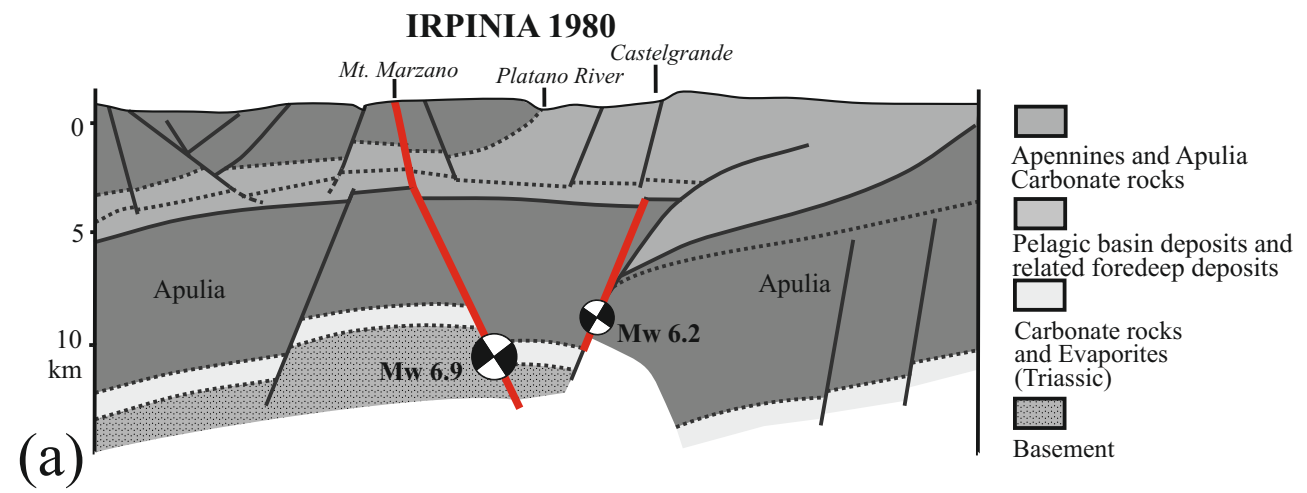

\section{COLFIORITO 1997}

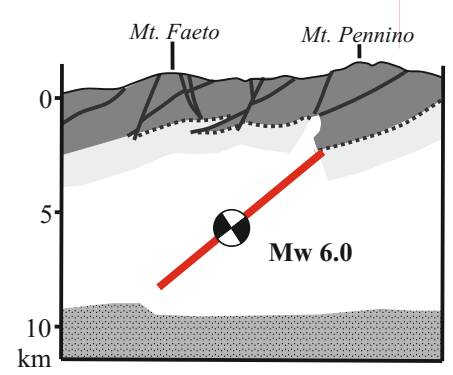

(b)

\section{CAMPOTOSTO 2009 (Cross-Section 4)}

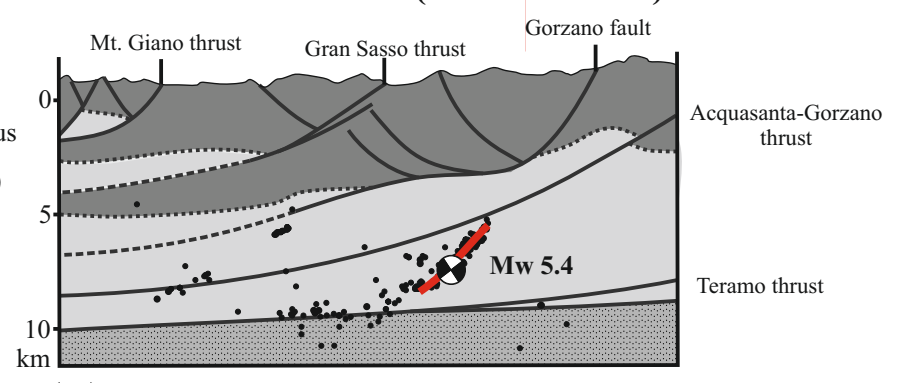

(c)

Figure 12. Geological cross sections across the causative faults of the 1980 Irpinia (modified from Mazzotti et al., 2007; faults from Pantosti and Valensise, 1990), 1997 Colfiorito (modified from Chiaraluce et al., 2005), and 2009 Campotosto (from Bigi et al., 2013) earthquakes. Thick red lines represent the seismogenic sources (Category I). 
play an indirect role in the assessment of ground shaking hazards.

III. Bending-moment secondary surface faults (i.e., Paganica ruptures): they represent breaks that are generated by the crustal bending taking place above the uppermost portion of the master fault. As such they are expected to (a) occur near the upward prolongation of the deeper master fault, thus simulating primary surface faulting, and (b) be restricted to the middle of the master fault, where slip is usually larger and bending is consequently tightest. Bending moment faults are also expected to nucleate at the surface and to extend downward up to a depth controlled by the bending geometry. They may cause sizable and somehow unpredictable surface faulting hazards.

IV. Inherited surface faults (e.g., the Bazzano and Pettino faults): they are faults formed during previous deformation phases and correspond mostly to faults bounding piggy-back basins, or more in general accompanying the progression of thrusting during the construction of the chain. They are usually very evident in the field and may or may not be reactivated, depending on their location and geometry relative to the coseismic strain pattern imposed by the master fault. They may be relevant to the assessment of ground shaking hazard due to faulttrapped waves (Calderoni et al., 2012), whereas due to their clear visibility they pose a limited surface faulting hazard.

\subsection{Seismogenic sources in the Italian Apennines: the challenge of youthful normal faulting}

The complex interaction of the recent to currently active extension with the inherited tectonic setting of the L'Aquila area once again suggests that relating the seismogenic source to its surface expressions may be a very challenging task. For the same reasons, anticipating the location of major seismogenic sources based on their presumed surface expression is a difficult and potentially misleading exercise that may have crucial implications for the assessment of local seismic hazards.

With proper consideration of local geological and tectonic peculiarities, the causative faults of other normal faulting earthquakes that struck the Apennines during the past century can be revisited following our observations on the L'Aquila seismotectonic scenario.

The 23 November 1980, Irpinia, Southern Apennines earthquake $\left(M_{\mathrm{w}} 6.9\right)$ was generated by a seismogenic fault (Category I) that clearly reached the surface over a distance of nearly $40 \mathrm{~km}$ (Pantosti and Valensise, 1990: Fig. 12a). This causative fault is directly visible, but it is worth recalling that the observed ruptures did not bound any intermontane basin, but rather crossed the landscape, showing a tendency to reverse the existing topographic setting. In the same geolog- ical context, the presumed causative fault of a large mainshock subevent that occurred $40 \mathrm{~s}$ after nucleation with an estimated $M_{\mathrm{w}} 6.2$ was a blind antithetic fault confined in the Apulia carbonate rocks (Pantosti and Valensise, 1990). The observed lateral fragmentation of the 1980 earthquake source can be interpreted as related to the widespread occurrence of preexisting tectonic boundaries interacting with the master fault at depth. These features can be assigned to our Category II (Inherited subsurface faults).

In contrast, the 26 September 1997 Umbria-Marche complex sequence in the central-northern Apennines $\left(M_{\mathrm{w}} 6.0\right)$ did not generate sizable surface breaks (e.g., Basili et al., 1998), and the available knowledge on the location and geometry of the seismogenic sources shows that they do not connect with any of the known range-bounding faults (e.g., Barba and Basili, 2000). The surface faults that displayed some rejuvenation of the bedrock fault plane should hence be assigned to our Category IV (Inherited surface faults).

The catastrophic 13 January 1915 Avezzano earthquake $\left(M_{\mathrm{w}} 6.8\right)$ in the Abruzzi Apennines caused large coseismic surface breaks within the large Fucino intramontane basin. Some of the observed ruptures (e.g., the San Benedetto fault scarp, Michetti et al., 2004), however, occurred away from the basin boundaries, suggesting that some of the rejuvenated bedrock faults should be assigned to our Category IV (Inherited surface faults).

Coming back to the region of the 2009 L'Aquila earthquake, it is known that the northernmost portion of the aftershock sequence, located near Lake Campotosto, activated a further seismogenic fault system that released a $M_{\mathrm{w}} 5.4$ event on 9 April 2009 (Bigi et al., 2013). This earthquake and its aftershocks occurred in a crustal volume confined both at the bottom and at the top by thrust faults inherited from the extinct compressional tectonic regime, and which for this reason should be assigned to our Category II (Inherited subsurface faults: Fig. 12c). This further strengthens the view that inherited thrust faults played a significant role as well in the L'Aquila earthquake.

In summary, seismogenic master faults may or may not reach the surface and cause primary surface faulting, depending on their size and depth, the amount of slip and its distribution on the fault plane, and the presence of favorably oriented, inherited discontinuities in the surrounding crustal volume (see Category II). Such down-dip segmentation may also be caused by velocity strengthening zones along the fault plane, or by the fault interaction with generic mechanical discontinuities within the host rocks (e.g., weak rock layers).

The geological expression of the Italian earthquakes leads to a sort of "reversed tectonic hierarchy", such that the main seismogenic fault (Category I) may be expressed at the surface only by rather subdued bending-moment faults (Category III), may be constrained in length and width by preexisting faults and discontinuities (Category II), and may lie hidden beneath a blanket of clearly visible yet substantially harmless faults (Category IV). 

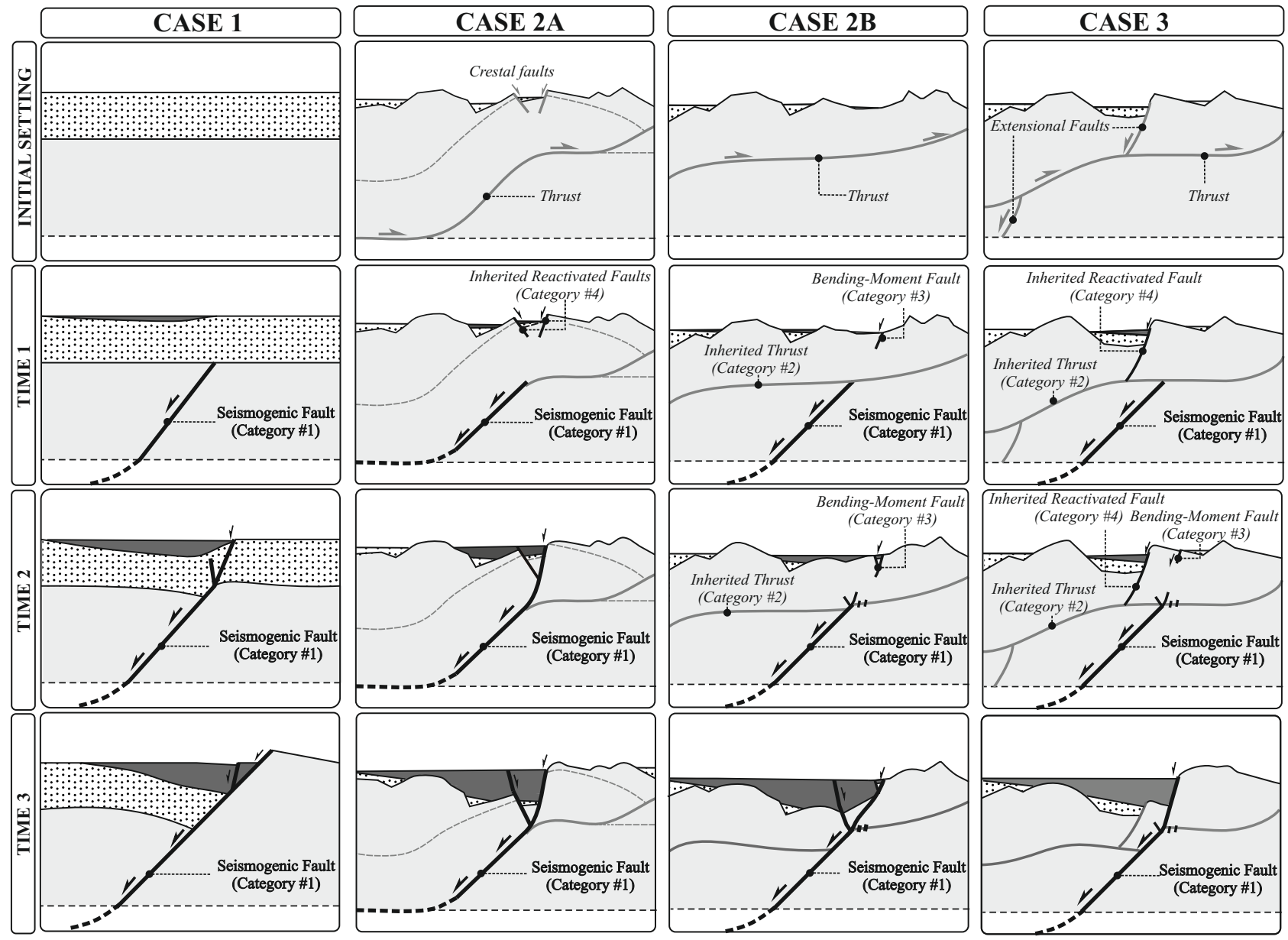

Figure 13. Images showing an inferred sequential development of a seismogenic master fault (Category \#1) and its ancillary structures (Category \#2, Category \#3, and Category \#4) in four different tectonic scenarios. Gray and black lines represent inherited structures and active faults, respectively. The panels labeled TIME 1, TIME 2 and TIME 3 show successive steps of fault evolution. In CASE 1 the initial setting does not exhibit significant inherited mechanical discontinuities; the seismogenic fault easily reaches the surface. CASE 2 (A and B) comprises two scenarios of geodynamic change, i.e., from compression to extension. In CASE 2A the seismogenic master fault (Category $\# 1$ ) is an inherited thrust ramp (Category \#2) reactivated since the early stages of extension (TIME 1); crestal faults that developed along the extrados of the thrust-related fold may be reactivated (Category \#4), mimicking a surface-breaking master fault. In CASE 2B an inherited thrust plays a segmentation role (Category \#2) and slows down the upward propagation of the master fault, causing extreme bending of the surface rather than faulting and promoting the creation of bending-moment faults (Category \#3). CASE 3 is the most complex, as it shows a scenario of both positive and negative inversion. The seismogenic fault interacts with an inherited thrust at shallower crustal levels, generating bending-moment faults (Category \#3) and remobilizing an inherited extensional fault plane that simulates a fully primary surface rupture.

\section{Conclusions}

Our analysis of seismogenic faulting in the L'Aquila area reveals an unprecedented complexity in the interaction between coseismic slip and inherited structural features. In particular, it suggests that the main surface coseismic rupture related to the 2009 L'Aquila earthquake - the Paganica fault - can be better explained as a result of surface bending rather than as the direct prolongation of the seismogenic master fault. Under these circumstances, the length of the faulted zone and the extent of surface slip would be controlled more by the rheology of the shallow rocks than by the fault slip at depth. This would ultimately prevent the surface rupture parameters from being used to obtain the earthquake magnitude using empirical relationships (e.g., Wells and Coppersmith, 1994), both for the considered event and for previous earthquakes detected through paleoseismological trenching.

We believe that the 2009 L'Aquila earthquake illustrates well the nature of the interaction between the seismogenic fault and other inherited structures at depth (e.g., buried thrust planes), the partial reactivation of inherited surface faults (e.g., the Bazzano, Mt. Stabiata and Pettino faults), and the occurrence of pseudo-primary surface ruptures (the Paganica fault). We contend that the 6 April 2009 L'Aquila 
earthquake in fact illustrates a common style of complex tectonic deformation, implying that the number of unrecognized, blind or hidden seismogenic faults in Italy - and probably elsewhere - could be larger than previously thought. Driven by the current tectonic regime such faults break through a highly complex upper crust, interacting in various ways with the existing structural fabric. This may result in limitations in their size, reactivation of inherited faults and generation of new surface breaks (Fig. 13). What is absolutely crucial for the geological reconnaissance work is that in the field these highly diverse faults may exhibit a reversed hierarchy, the most obvious being the least relevant in a faultbased seismic hazard assessment and vice versa. Proper appreciation of such complexity forms the basis for a correct assessment of the local earthquake potential.

From this perspective, the work and the ideas we presented have obvious and important implications in the context of seismic hazard assessment. The "... ability to distinguish between tectonically induced primary and secondary faulting, faulting induced by strong ground motions, and faulting induced by nontectonic phenomena ..." has been seen by Hanson et al. (1999) as a fundamental pre-requisite for devising appropriate regulatory criteria in the siting of nuclear power plants and other critical facilties. McCalpin (2000), among several others, discussed strategies for the analysis of secondary features associated with the distributed expression of reverse faulting, including bending-moment faults, flexuralslip faults and folds, and placed them in a hierarchical classification. Much of their work, however, deals with secondary faulting induced by blind faults in compressional environments, because this is the dominating tectonic style in the countries where these studies were initiated. So far there has been little appreciation for the fact that the same features and interpretative problems may also be seen in extensional environments: our study aims to fill this gap using the unique evidence from the 2009 earthquake.

Italy no longer has nuclear facilities in operation, but it is a highly seismic country that hosts a large fraction of the worldwide cultural heritage. Not all areas are equally at risk, hence any building retrofitting strategy requires priorities to be set based on careful examination of the true seismogenic potential of each individual seismogenic area. Much work has already been carried out on the potential of Italian faults, and several quiescent areas are being watched closely following the identification of presumed active tectonic features. The results of our analysis suggest that an objective evaluation of the hazard posed by any recognized active fault requires full and proper appreciation of its true hierarchy level. This is to be achieved by blending surface, subsurface, geomorphic, structural and seismological data and, more importantly, by avoiding preconceptions and overly simplified models.
Acknowledgements. This work was financially supported by Regione Lombardia, by the Italian Ministry of Research and Education (MIUR) in the framework of INGV's Progetto Abruzzo, and by Presidenza del Consiglio dei Ministri - Dipartimento della Protezione Civile (DPC). The views and conclusions contained in this paper are those of the authors and should not be interpreted as necessarily representing official opinions and policies, either expressed or implied, of the Italian Government. The editor F. Storti and the referee K. Decker are gratefully acknowledged for the review and the constructive criticisms that improved this paper.

Edited by: F. Storti

\section{References}

Atzori, S., Hunstad, I., Chini, M., Salvi, S., Tolomei, C., Bignami, C., Stramondo, S., Trasatti, E., Antonioli, A., and Boschi, E.: Finite fault inversion of DInSAR coseismic displacement of the 2009 L'Aquila earthquake (central Italy), Geophys. Res. Lett., 36, L15305, doi:10.1029/2009GL039293, 2009.

Barba, S. and Basili, R.: Analysis of seismological and geological observations for moderate-size earthquakes: the Colfiorito Fault System (Central Apennines, Italy), Geophys. J. Int., 141, 241252, 2000.

Basili, R., Bosi, V., Galadini, F., Galli, P., Meghraoui, M., Messina, P., Moro, M., and Sposato, A.: The Colfiorito earthquake sequence of September-October 1997: Surface breaks and seismotectonic implications for the central Apennines (Italy), J. Earthq. Eng., 2, 291-302, 1998.

Bianchi, I., Chiarabba, C., and Piana Agostinetti, N.: Control of the 2009 L'Aquila earthquake, central Italy, by a high-velocity structure: A receiver function study, J. Geophys. Res., B12326, doi:10.1029/2009JB007087, 2010..

Bigi, S., Casero, P., Chiarabba, C., and Di Bucci, D.: Contrasting surface active faults and deep seismogenic sources unveiled by the 2009 L'Aquila earthquake sequence (Italy), Terra Nova, 25, 1, 21-29, doi:10.1111/ter.12000, 2013.

Boncio, P., Pizzi, A., Brozzetti, F., Pomposo, G., Lavecchia, G., Di Naccio, D., and Ferrarini, F. : Coseismic ground deformation of the 6 April 2009 L'Aquila earthquake (central Italy, $M_{\mathrm{W}} 6.3$ ), Geophys. Res. Lett., 37, L06308, doi:10.1029/2010GL042807, 2010.

Bonini, L., Di Bucci, D., Toscani, G., Seno, S., and Valensise, G.: Reconciling deep seismogenic and shallow active faults through analogue modeling; the case of the Messina Straits (southern Italy), J. Geol. Soc. Lond., 168, 191-199. 2011.

Brace, W. F. and Byerlee, J. D.: California earthquakes: Why only shallow focus?, Science, 168, 1573-1575, 1970.

Calamita, F., Satolli, S., Scisciani, V., Esestime, P., and Pace, P.: Contrasting styles of fault reactivation in curved orogenic belts: Examples from the Central Apennines (Italy), Geol. Soc. Am. Bull., 123, 1097-1111, 2011.

Calderoni, G., Di Giovambattista, R., Vannoli, P., Pucillo, S., and Rovelli, A.: Fault-trapped waves depict continuity of the fault system responsible for the 6 April $2009 M_{\mathrm{W}} 6.3$ L'Aquila earthquake, central Italy, Earth Planet. Sci. Lett., 323-324, 1-8, 2012. 
Carafa, M. M. C. and Barba, S.: The stress field in Europe: optimal orientations with confidence limits, Geophys. J. Int., 193, 531548, doi:10.1093/gji/ggt024, 2013.

Chiarabba, C., Amato, A., Anselmi, M., Baccheschi, P., Bianchi, I., Cattaneo, M., Cecere, G., Chiaraluce, L., Ciaccio, M.G., De Gori, P., De Luca, G., Di Bona, M., Di Stefano, R., Faenza, L., Govoni, A., Improta, L., Lucente, F. P., Marchetti, A., Margheriti, L., Mele, F., Michelini, A., Monachesi, G., Moretti, M., Pastori, M., Piana Agostinetti, N., Piccinini, D., Roselli, P., Seccia, D., and Valoroso, L.: The 2009 L'Aquila (central Italy) $M_{\mathrm{W}} 6.3$ earthquake: main shock and aftershocks, Geophys. Res. Lett., 36, L18308, doi:10.1029/2009GL039627, 2009.

Chiarabba, C., Bagh, S., Bianchi, I., De Gori, P., and Barchi, M.: Deep structural heterogeneities and the tectonic evolution of the Abruzzi region (Central Apennines, Italy) revealed by microseismicity, seismic tomography, and teleseismic receiver functions, Earth Planet. Sci. Lett., 295, 3, 462-476, 2010.

Cheloni, D., D’Agostino, N., D’Anastasio, E., Avallone, A., Mantenuto, S., Giuliani, R., Mattone, M., Calcaterra, S., Gambino, P., Dominici, D., Radicioni, F., and Fastellini, G.: Coseismic and initial post-seismic slip of the $2009 M_{\mathrm{W}} 6.3$ L'Aquila earthquake, Italy, from GPS measurements, Geophys. J. Int., 181, 15391546, 2010.

Cheloni, D., Giuliani, R., D’Anastasio, E., Atzori, S., Walters, R. J., Bonci, L., D’Agostino, N., Mattone, M., Calcaterra, P., Deninno, R., Maseroli, R., and Stefanelli, G.: Coseismic and post-seismic slip of the 2009 L'Aquila (central Italy) $M_{\mathrm{W}} 6.3$ earthquake and implications for seismic potential along the Campotosto fault from joint inversion of high-precision levelling, InSAR and GPS data, Tectonophysics, doi:10.1016/j.tecto.2014.03.009, 2014.

Chiaraluce, L.: Unravelling the complexity of Apenninic extensional fault systems: A review of the 2009 L'Aquila earthquake (Central Apennines, Italy), J. Struct. Geol., 42, 2-18, 2012.

Chiaraluce, L., Barchi, M., Collettini, C., Mirabella, F., and Pucci, S.: Connecting seismically active normal faults with Quaternary geological structures in a complex extensional environment: The Colfiorito 1997 case history (northern Apennines, Italy), Tectonics, 24, TC1002, doi:10.1029/2004TC001627, 2005.

Chiaraluce, L., Valoroso, L., Piccinini, D., Di Stefano, R., and De Gori, P.: The anatomy of the 2009 L'Aquila normal fault system (central Italy) imaged by high resolution foreshock and aftershock locations, J. Geophys. Res., 116, B12311, doi:10.1029/2011JB008352, 2011

Cinti, F. R, Pantosti, D., De Martini, P. M., Pucci, S., Civico, R., Pierdominici, S., Cucci, L., Brunori, C. A., Pinzi, S., and Patera, A.: Evidence for surface faulting events along the Paganica fault prior to the 6 April 2009 L'Aquila earthquake (central Italy), J. Geophys. Res., 116, B07308, doi:10.1029/2010JB007988, 2011.

Cirella, A., Piantanesi, A., Cocco, M., Tinti, E., Scognamiglio, L., Michelini, A., Lomax, A., and Boschi, E.: Rupture history of the 2009 L'Aquila (Italy) earthquake from non-linear joint inversion of strong motion and GPS data, Geophys. Res. Lett., 36, L19304, doi:10.1029/2009GL039795, 2009.

Cloos, E.: Experimental analysis of Gulf Coast fracture patterns, AAPG Bulletin, 52, 420-444, 1968.

Cooke, M. L., Schottenfeld, M. T., and Buchanan, S. W.: Evolution of fault efficiency at restraining bends within wet kaolin analog experiments, J. Struct. Geol., 51, 180-192, 2013.
Cooke, M. L. and van der Elst, N. J.: Rheologic testing of wet kaolin reveals frictional and bi-viscous behaviour typical of crustal materials, Geophys. Res. Lett., 39, L01308, doi:10.1029/2011GL050186, 2012.

D’Agostino, N., Cheloni, D., Fornaro, G., Giuliani, R., and Reale, D.: Space-time distribution of afterslip following the 2009 L'Aquila earthquake, J. Geophys. Res., 117, B02402, doi:10.1029/2011JB008523, 2012.

D’Agostino, N., Mantenuto, S., D'Anastasio, E., Giuliani, R., Mattone, M., Calcaterra, S., Gambino, P., and Bonci, L.: Evidence for localized active extension in the central Apennines (Italy) from Global Positioning System observation, Geology, 39, 291-294, 2011.

D’Anastasio, E., De Martini, P. M., Selvaggi, G., Pantosti, D., Marchioni, A., and Maseroli, R.: Short-term vertical velocity field in the Apennines (Italy) revealed by geodetic levelling data, Tectonophysics, 418, 219-234, 2006.

Di Domenica, A., Bonini, L., Fernando, C., Toscani, G., Galuppo, C., and Seno, S.: Analogue modeling of positive inversion tectonics along differently oriented pre-thrusting normal faults: An application to the Central-Northern Apennines of Italy, Geol. Soc. Am. Bull., doi:10.1130/B31001.1, 2014.

Di Stefano, R., Chiarabba, C., Chiaraluce, L., Cocco, M., De Gori, P., Piccinini, D., and Valoroso, L.: Geophys. Res. Lett. 38, L10310, doi:10.1029/2011GL047365, 2011.

Eisenstadt, G. and Sims, D.: valuating sand and clay models; do rheological differences matter? J. Struct. Geol., 27, 1399-1412, 2005.

Emergeo Working Group: Evidence for surface rupture associated with the $M_{\mathrm{W}} 6.3$ L'Aquila earthquake sequence of April 2009 (central Italy), Terra Nova, 22, 43-51, 2010.

Erslev, E. A.: Trishear fault-propagation folding, Geology, 19, 617-620, doi:10.1130/00917613(1991)019<0617:TFPF>2.3.CO;2,1991.

Galadini, F.: Pleistocene changes in the central Apennine fault kinematics: a key to decipher active tectonics in central Italy, Tectonics, 18, 877-894, 1999.

Geological Map of Italy: L'Aquila sheet, n. 359, 1 : 50000 scale, available at: http://www.isprambiente.gov.it/MEDIA/carg/359_ LAQUILA/Foglio.html, 2009.

Graveleau, F., Malavieille, J., and Dominguez, S.: Experimental modelling of orogenic wedges: a review, Tectonophysics, 538540, 1-66, 2012.

Gori, S., Falcucci, E., Dramis, F., Galadini, F., Galli, P., Giaccio, B., Messina, P., Pizzi, A. Sposato, A., and Cosentino, D.: Deepseated gravitational slope deformation, large-scale rock failure, and active normal faulting along Mt. Morrone (Sulmona basin, Central Italy): Geomorphological and paleoseismological analyses, Geomorfology, 208, 88-101, 2014.

Hanson, K. L., Kelson, K. I., Angell, M. A., and Lettis, W. R.: Techniques for identifying faults and determining their origins, NUREG/CR-5503, U.S. Nuclear Regulatory Commission, 1999.

Hardy, S. and Ford, M.: Numerical modeling of trishear fault propagation folding, Tectonics, 16, 841-854, doi:10.1029/97TC01171, 1997.

Henza, A., Withjack, M. O., and Schlische, R. W.: Normalfault development during two phases of non-coaxial extension: An experimental study, J. Struct. Geol., 32, 1656-1667, doi:10.1016/j.jsg.2009.07.007, 2010. 
Herrmann, R. B., Malagnini, L., and Munafò, I.: Regional moment tensors of the 2009 L'Aquila earthquake sequence, Bull. Seismol. Soc. Am., 101, 975-993, 2011.

Hyppolite, J.-C., Angelier, J., and Roure, F.: A major geodynamic change revealed by Quaternary stress patterns in the Southern Apennines (Italy), Tectonophysics, 230, 199-210, 1994.

Hubbert, M. K.: Theory of scale models as applied to the study of geologic structures, Geol. Soc. Am. Bull., 48, 1459-1520, 1937.

Improta, L., Villani, F., Bruno, P. P., Castiello, A., De Rosa, D., Varriale, F., Punzo, M., Brunori, C. A., Civico, R., Pierdominici, S., Berlusconi, A., and Giacomuzzi, G.: High-resolution controlledsource seismic tomography across the Middle Aterno basin in the epicentral area of the $2009, M_{\mathrm{W}} 6.3$, L'Aquila earthquake (central Apennines, Italy), Ital. J. Geosci., 131, 373-388, 2012.

Jin, G. and Groshong Jr., R. H.: Trishear kinematic modeling of extensional fault-propagation folding, J. Struct. Geol., 28 , 170183, 2006.

Kim, Y.-S. and Sanderson, D. J.: The relationship between displacement and length of faults: a review, Earth-Sci. Rev., 68, 317-334, 2005.

Lin, J. and Stein, R. S.: Stress triggering in thrust and subduction earthquakes and stress interaction between the southern San Andreas and nearby thrust and strike-slip faults, J. Geophys. Res., 109, B02303, doi:10.1029/2003JB002607, 2004.

Mandl, G.: Faulting in brittle rocks: an introduction to the mechanics of tectonic faults, Springer Berlin, 2000.

Mazzotti, A., Stucchi, E., Fradelizio, G. L., Zanzi, L., and Scandone, P.: Re-processing of the CROP-04 seismic data: Bollettino della Società Geologica Italiana, 7, 141-153, 2007.

McCalpin, J. P.: Paleoseismology, Academic Press, 2 Edn., 647 pp, 2009.

Marone, C. and Scholz, C. H.: The depth of seismic faulting and the upper transition from stable to unstable slip regimes, Geophys. Res. Lett., 15, 621-624, 1988.

Michetti, A. M., Brunamonte, F., Serva, L., and Vittori, E.: Trench investigations of the 1915 Fucino earthquake fault scarp (Abruzzo, central Italy): geological evidence of large historical events, J. Geophys. Res., 101, 5921-5936, 1996.

Miller, J. F. and Mitra, S.: Deformation and secondary faulting associated with basement-involved compressional and extensional structures, AAPG Bull., 95, 675-689, 2011.

Montone, P., Mariucci, M. T., and Pierdominici, S.: The Italian present-day stress map, Geophys. J. Int., 189, 705-716, 2012.

Pantosti, D. and Valensise, G.: Faulting mechanism and complexity of the 23 November, 1980, Campania-Lucania earthquake inferred from surface observations, J. Geophys. Res., 95, 1531915341, 2000.

Patacca, E. and Scandone, P.: Post-Tortonian mountain building in the Apennines. The role of the passive sinking of a relic lithospheric slab, in: The Lithosphere in Italy, edited by: Boriani, A., Bonafede, M., Piccardo, G. B., and Vai, G. G., Accademia dei Lincei, Roma, 157-176, 1989.

Perfettini, H. and Ampuero, J.-P.: Dynamics of a velocity strengthening fault region: Implications for slow earthquakes and postseismic slip, J. Geophys. Res., doi:10.1029/2007JB005398, 11, 901-11, B09411, 912, 2008.

Satolli, S. and Calamita, F.: Differences and similarities between the Central and the Southern Apennines (Italy): examining the Gran Sasso vs. the Matese-Frosolone salients using paleomag- netic, Geological and Structural Data, J. Geophys. Res., 113, B10101, doi:10.1029/2008JB005699, 2008.

Schellart, W. P.: Shear test results for cohesion and friction coefficients for different granular materials: scaling implications for their usage in analogue modeling, Tectonophysics, 324, 1-16, 2000.

Scholz, C. H.: The brittle-plastic transition and the depth of seismic faulting, Geol. Rundsch. 77, 319-328, 1988.

Scholz, C. H.: The mechanics of earthquakes and faulting, Cambridge University Press, 439 pp, 1990.

Scisciani, V., Tavarnelli, E., and Calamita, F.: The interaction of extensional and contractional deformations in the outer zones of the Central Apennines, Italy, J. Struct. Geol., 24, 1647-1658.

Scognamiglio, L., Tinti, E., Michelini, A., Dreger, D. S., Cirella, A., Cocco, M., Mazza, S., and Piatanesi, A.: Fast determination of moment tensors and rupture history: What has been learned from the 6 April 2009 L'Aquila earthquake sequence, Seismol. Res. Lett., 81, 892-906. 2010.

Stirling, M., Goded, T., Berryman, K., and Litchfield, N.: Selection of Earthquake Scaling Relationships for Seismic-Hazard Analysis, Bull. Seismol. Soc. Am., 103, 1-19, 2013.

Valensise, G. and Pantosti, D.: The investigation of potential earthquake sources in peninsular Italy: a review, J. Seismol., 5, 287 306, 2001.

Valoroso, L., Chiaraluce, L., Piccinini, D., Di Stefano, R., Schaff, D., and Waldhauser, F.: Radiography of a normal fault system by 64,000 high-precision earthquake locations: the 2009? L'Aquila (central Italy) case study., J. Geophys. Res., doi:10.1002/jgrb.50130, 2013.

van Gent, H. W., Holland, M., Urai, J. L., Loosveld, R.: Evolution of fault zones in carbonates with mechanical stratigraphy - Insights from scale models using layered cohesive powder, J. Struct. Geol., 32, 1375-1391, 2010.

Vannoli, P., Burrato, P., Fracassi, U., and Valensise, G.: A fresh look at the seismotectonics of the Abruzzi (Central Apennines) following the 6 April 2009 L'Aquila earthquake $\left(M_{\mathrm{W}} 6.3\right)$, Ital. J. Geosci., 131, 309-329, 2012.

Vezzani, L., Festa, A., and Ghisetti, F.: Geological-structural map of the Central-Southern Apennines (Italy), 1:250,000 scale (S.E.L.CA. ed., Firenze), 2009.

Vittori, E., Di Manna, P., Blumetti, A. M., Comerci, V., Guerrieri, L., Esposito, E., Michetti, A. M., Porfido, S., Piccardi, L., Roberts, G. P., Berlusconi, A., Livio, F., Sileo, G., Wilkinson, M., McCaffrey, K. J. W., Phillips, R. J., and Cowie P. A.: Surface Faulting of the 6 April $2009 M_{\mathrm{W}} 6.3$ L'Aquila Earthquake in Central Italy, Bull. Seismol. Soc. Am., 101, 1507-1530, 2011.

Wells, D. L. and Coppersmith, K. J.: New empirical relationships among magnitude, rupture length, rupture width, rupture area, and surface displacement, Bull. Seismol. Soc. Am., 84, 9741002, 1994.

Wesnousky, S. G.: Displacement and geometrical characteristics of earthquake surface ruptures: Issues and implications for seismic hazard analysis and the earthquake rupture process, Bull. Seismol. Soc. Am., 98, 1609-1632, 2008.

Withjack, M. O. and Jamison, W. R.: Deformation produced by oblique rifting, Tectonophysics, 126, 99-124, doi:10.1016/00401951(86)90222-2, 1986. 
Withjack, M. O. and Schlische, R. W.: Geometric and experimental models of extensional fault-bend folds, Geol. Soc. Spec. Pub., 253, 285-305, 2006.
Withjack, M. O., Schlische, R. W, and Henza, A. A.: Scaled experimental models of extension: dry sand vs. wet clay, Houston Geol. Soc. Bull., 49, 31-49, 2007. 